\title{
Identification of prognostic biomarkers for patients withhepatocellular carcinoma after hepatectomy
}

\author{
XIANGKUN WANG ${ }^{1}$, XIWEN LIAO $^{1}$, CHENGKUN YANG $^{1}$, KETUAN HUANG $^{1}$, \\ TINGDONG YU ${ }^{1}$, LONG YU ${ }^{1,2}$, CHUANGYE HAN ${ }^{1}$, GUANGZHI ZHU ${ }^{1}$, XIANMIN ZENG ${ }^{1}$,

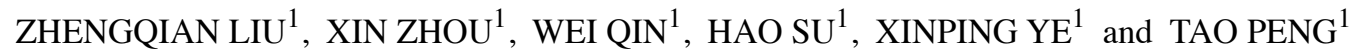 \\ ${ }^{1}$ Department of Hepatobiliary Surgery, The First Affiliated Hospital of Guangxi Medical University, \\ Nanning, Guangxi 530021; ${ }^{2}$ Department of Hepatobiliary and Pancreatic Surgery, \\ The First Affiliated Hospital of Zhengzhou University, Zhengzhou, Henan 450000, P.R. China
}

Received August 22, 2018; Accepted November 28, 2018

DOI: 10.3892/or.2019.6953

\begin{abstract}
Hepatocellular carcinoma (HCC) is a lethal malignancy with high morbidity and mortality rates worldwide. The identification of prognosis-associated biomarkers is crucial to improve HCC patient survival. The present study aimed to explore potential predictive biomarkers for HCC. Differentially expressed genes (DEGs) were analyzed in the GSE36376 dataset using GEO2R. Hub genes were identified and further investigated for prognostic value in HCC patients. A risk score model and nomogram were constructed to predict HCC prognosis using the prognosis-associated genes and clinical factors. Pearson's correlation was employed to show interactions among hub genes. Gene enrichment analysis was performed to identify detailed biological processes and pathways. A total of 71 DEGs were obtained and seven $(A D H 4, C Y P 2 C 8, C Y P 2 C 9$, CYP8B1, SLC22A1, TAT and HSD17B13, all adjusted $\mathrm{P} \leq 0.05$ ) of the 10 hub genes were identified as prognosis-related genes for survival analysis in HCC patients, including alcohol dehydrogenase 4 (class II), pi polypeptide $(A D H 4)$, cytochrome p450 family 2 subfamily C member 8 (CYP2C8), cytochrome P450 family 2 subfamily $\mathrm{C}$ member 9 (CYP2C9), cytochrome
\end{abstract}

Correspondence to: Professor Tao Peng, Department of Hepatobiliary Surgery, The First Affiliated Hospital of Guangxi Medical University, 6 Shuangyong Road, Nanning, Guangxi 530021, P.R. China

E-mail: pengtaogmu@163.com

Abbreviations: HCC, hepatocellular carcinoma; GEO, Gene Expression Omnibus; DEG, differentially expressed gene; PPI, protein-protein interaction; GEPIA, Gene Expression Profiling Interactive Analysis; ROC, receiver operating characteristic; AUC, area under the curve; HR, hazard ratio; CI, confidence interval; MST, median survival time; GO, Gene Ontology; BP, biological process; CC, cellular component; MF, molecular function; KEGG, Kyoto Encyclopedia of Genes and Genomes; DAVID, Database for Annotation, Visualization and Integrated Discovery

Key words: hepatocellular carcinoma, prognosis, differentially expressed genes, serum biomarker, risk score model
P450 family 8 subfamily B member 1 (CYP8B1), solute carrier family 22 member 1 (SLC22A1), tyrosine aminotransferase (TAT) and hydroxysteroid 17- $\beta$ dehydrogenase 13 (HSD17B13). The risk score model could predict HCC prognosis and the nomogram visualized gene expression and clinical factors of probability for HCC prognosis. The majority of genes showed significant Pearson's correlations with others (41 Pearson correlations $\mathrm{P} \leq 0.01$, four Pearson correlations $\mathrm{P}>0.05$ ). GO analysis revealed that terms such as 'chemical carcinogenesis' and 'drug metabolism-cytochrome P450' were enriched and may prove helpful to elucidate the mechanisms of hepatocarcinogenesis. Hub genes $A D H 4, C Y P 2 C 8, C Y P 2 C 9, C Y P 8 B 1$, $S L C 22 A 1, T A T$ and $H S D 17 B 13$ may be useful as predictive biomarkers for $\mathrm{HCC}$ prognosis.

\section{Introduction}

Liver cancer is more common in men than in women, and is the second leading cause of cancer-associated mortality worldwide in men living in less developed countries (1). It is estimated that $\sim 50 \%$ of newly diagnosed cancer cases and mortalities globally occurred in China alone in 2012, which equates to approximately 391,250 new liver cancer cases and 372,750 mortalities (1). Hepatocellular carcinoma (HCC) accounts for the majority (70-90\%) of primary liver cancer cases worldwide (2). Previous epidemiological surveys have revealed that chronic hepatitis $\mathrm{B}$ or $\mathrm{C}$ viral infection, cirrhosis, exposure to aflatoxin $\mathrm{B} 1$, obesity, chronic alcohol consumption and diabetes mellitus, as well as metabolic abnormalities including haemochromatosis and $\alpha 1$-antitrypsin deficiency, are common and significant risk factors for HCC development (3-5). Furthermore, recent studies indicate that approximately 1,000,000 new HCC cases are diagnosed each year worldwide, with the same incidence and morbidity rate, indicating that $\mathrm{HCC}$ diagnosis is typically at the advanced stage and prognosis remains poor (6,7). Despite advances in diagnosis, prevention and treatment, including ultrasonography, multiphase computerized tomography, magnetic resonance imaging, surgical resection, liver transplantation, transarterial chemoembolization, radiofrequency ablation and transarterial radiation, percutaneous ablation and 
systemic therapy, the prognosis for HCC patients remains unsatisfactory (8). The 5-year relative survival rate is approximately $7 \%$ (9). Therefore, identification of novel biomarkers for the early diagnosis of HCC is vital and may improve HCC prognosis.

At present, many reports have focused on the identification of prognosis-associated biomarkers The role of astrocytic phosphoprotein PEA-15 in HCC has been evaluated and may be a novel target for HCC treatment, as well as a predictive biomarker for HCC patient prognosis (10). Furthermore, it has been suggested that CKLF-like MARVEL transmembrane domain-containing protein 5 may function as a tumor suppressor in human HCC and represent a valuable therapeutic target (11). microRNA (miR)-182-5p is recognized as a potential predictive biomarker for the early recurrence of HCC (12). Currently, DNA microarray approach has been used to investigate the genetic features of HCC in molecular biology (13). Accumulating evidence regarding gene expression in HCC has demonstrated that a variety of differentially expressed genes (DEGs) may be involved in the process of hepatocarcinogenesis (14). The combination of microarray techniques and bioinformatic analysis makes it conceivable to use DEGs in one or more chips to detect potential predictive biomarkers for several types of malignancies (15). Therefore, the present study focused on DEGs in microarrays and aimed to identify potential predictive biomarkers for patients with HCC.

\section{Materials and methods}

Data collection and processing. GEO2R (www.ncbi.nlm.nih. gov/geo/geo2r/) was initially used to identify DEGs in the GSE36376 gene expression profile in the Gene Expression Omnibus (GEO) database (16). The GSE36376 dataset (www.ncbi.nlm.nih.gov/geo/query/acc.cgi?acc=GSE36376) is embedded in the platform GPL10558 (Illumina HumanHT-12 v4 Expression Beadchip) and includes 240 tumor tissues and 193 adjacent non-tumor tissues of two gene expression by array sets: A training set and validation set (17).

Next, DEGs from the GSE36376 profile were acquired using the GEO2R tool with the criteria of llog fold changel $\geq 2$ and $\mathrm{P} \leq 0.05$. Furthermore, the Cytoscape software (version 3.6.0) plugin, CentiScaPe (version 2.2), was employed to identify the top 10 hub genes in these DEGs on the basis of the following centralities: degree, betweenness and closeness (18).

Hub gene expression, survival and stratified analysis. The expression levels of 10 hub genes in multiple organs, as well as in tumor and non-tumor tissues were obtained from the GTEx portal (www.gtexportal.org/home) and the Gene Expression Profiling Interactive Analysis (GEPIA; gepia.cancer-pku. cn/index.html) server (19). Protein expression levels of the hub genes in liver tissue were obtained from The Human Protein Atlas (www.proteinatlas.org) (20). A co-expression matrix was constructed using R (version 3.5.0; www.r-project.org) to show Pearson correlations between two of these genes.

In addition, hub genes were further analyzed for their prognostic values using The Cancer Genome Atlas database (cancergenome.nih.gov/). The clinical characteristics of 360 HCC patients, including age, sex, race and tumor stage, were obtained and used in the analysis. Gene expression data were downloaded from the OncoLnc website (www.oncolnc.org) at median cut off. In addition, clinical data with statistically significant P-values $(\leq 0.05)$ were adjusted for further analysis to identify prognosis-associated genes. For the above identified genes, clinical data were stratified for further analysis.

Hub gene mutational and transcriptional analysis. The mutation status of hub genes using the cBioPortal website (www.cbioportal.org/) $(21,22)$. Furthermore, transcripts per million (TPM) of the hub genes in liver tissues were analyzed to identify transcription levels at the log scale $\left[\log _{2}(\mathrm{TPM}+1)\right]$ using the GEPIA website (gepia.cancer-pku. cn/index.html/) (19).

Construction of risk score model and nomogram. A risk score model was constructed based on the expression levels of prognosis-associated genes and the contribution coefficient $(\beta)$ of the multivariate Cox proportional hazards regression model. The formula of the model was as follows: risk score=expression of gene $1 \times \beta_{1}$ of gene gexpression of gene $_{2} \times \beta_{2}$ of gene ex $_{2}+\ldots$ + expression of gene $\mathrm{n}_{\mathrm{n}} \times \beta_{\mathrm{n}}$ of gene $_{\mathrm{n}}$. The risk score was then divided into high and low risk groups with the same cut-off criteria of gene expression. A Kaplan-Meier survival curve was drawn to predict patient survival. Prognostic receiver operating characteristic (ROC) curves were then created at 1-5 years.

A nomogram was also constructed based on seven prognosis-associated hub genes, clinical factors and tumor stage, to obtain patient survival at 1, 3 and 5 years. The contribution of each factor was limited to a maximum of 100 points.

Gene-gene and protein-protein interactions (PPI) network construction and functional enrichment analysis. To identify the biological processes and metabolic pathways of these hub genes, enrichment analysis of Gene Ontology (GO) was performed, including biological process (BP), cellular component (CC), and molecular function (MF), and Kyoto Encyclopedia of Genes and Genomes (KEGG) pathways using The Database for Annotation, Visualization and Integrated Discovery (DAVID; david.ncifcrf.gov/) $(15,23)$. In addition, visualized GO results were presented by the Cytoscape BinGO plugin version 3.6.0 (18,24). Gene-gene interaction networks were constructed using the GeneMANIA plugin (version 3.4.1) in Cytoscape software version 3.6.0 (25). The PPI network depicted interactions among these proteins and was constructed using the Search Tool for the Retrieval of Interacting Genes website (string-db.org/cgi/input.pl) (26).

Statistical analysis. Kaplan-Meier survival analysis by log rank test was used to calculate the median survival time (MST). Univariate and multivariate Cox proportional hazards models were used to calculate the hazard ratio (HR) and $95 \%$ confidence interval (CI). $\mathrm{P} \leq 0.05$ was considered to indicate a statistically significant difference. Box plots by unpaired t-test, survival curves and ROC curves including area under the curve (AUC) were produced using GraphPad version 7.0 (GraphPad Software, Inc., La Jolla, CA, USA). Statistical analysis was performed using SPSS software version 16.0 (SPPS, Inc., Chicago, IL, USA). 
Table I. Identified hub genes in the GSE36376 dataset and their screening centralities.

\begin{tabular}{lccc}
\hline Genes & Degree centralities & Betweenness centralities & Closeness centralities \\
\hline CYP2E1 & 37 & 362.1080892 & 0.009345794 \\
$T A T$ & 32 & 266.8918244 & 0.008928571 \\
CYP2A6 & 32 & 97.3346815 & 0.008064516 \\
$C Y P 8 B 1$ & 32 & 109.0359712 & 0.008064516 \\
$C Y P 2 C 9$ & 31 & 179.8498746 & 0.007874016 \\
$H S D 11 B 1$ & 31 & 333.8964087 & 0.008849558 \\
$H S D 17 B 13$ & 31 & 147.7138107 & 0.008403361 \\
$S L C 22 A 1$ & 30 & 84.7381197 & 0.008403361 \\
$C Y P 2 C 8$ & 29 & 36.7257238 & 0.007751938 \\
$A D H 4$ & 28 & 52.5113332 & 0.007575758 \\
\hline
\end{tabular}

CYP2E1, cytochrome P450 family 2 subfamily E member 1; TAT, tyrosine aminotransferase; $C Y P 2 A 6$, cytochrome P450 family 2 subfamily A member 6; CYP8B1, cytochrome P450 family 8 subfamily B member 1; CYP2C9, cytochrome P450 family 2 subfamily C member 9; $H S D 11 B 1$, hydroxysteroid $11-\beta$ dehydrogenase $1 ; H S D 17 B 13$, hydroxysteroid $17-\beta$ dehydrogenase $13 ; S L C 22 A 1$, solute carrier family 22 member 1; $C Y P 2 C 8$, cytochrome p450 family 2 subfamily $\mathrm{C}$ member 8; $A D H 4$, alcohol dehydrogenase 4 (class II), pi polypeptide.
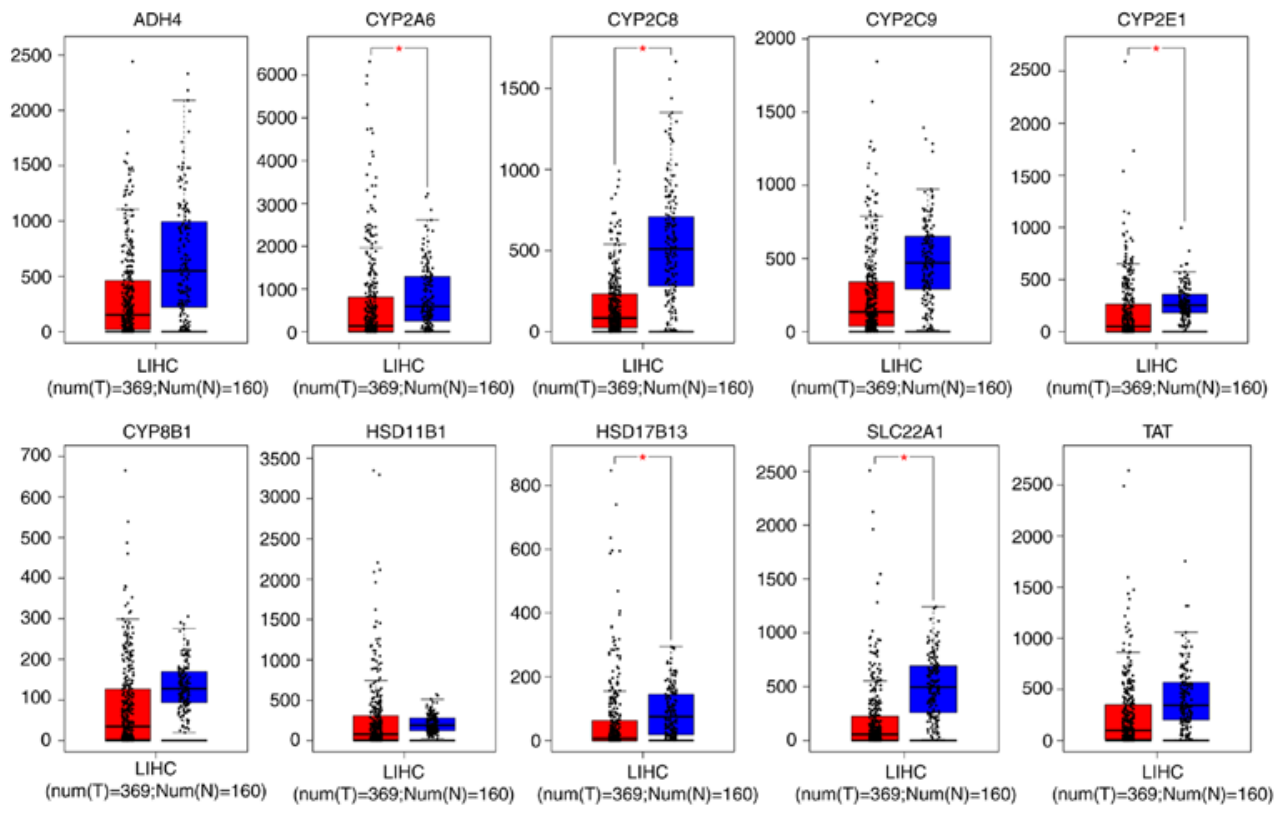

Tumor tissue

Normal tissue

Figure 1. Expression levels of hub genes $A D H 4, C Y P 2 A 6, C Y P 2 C 8, C Y P 2 C 9, C Y P 2 E 1, C Y P 8 B 1, H S D 11 B 1, H S D 17 B 13, S L C 22 A 1$ and $T A T$ in tumor and normal tissues. * $\mathrm{P}<0.05$ vs. normal tissue. LIHC, liver hepatocellular carcinoma; $C Y P 2 E 1$, cytochrome P450 family 2 subfamily E member $1 ;$ TAT, tyrosine aminotransferase; $C Y P 2 A 6$, cytochrome $\mathrm{P} 450$ family 2 subfamily A member 6; $C Y P 8 B 1$, cytochrome P450 family 8 subfamily B member 1; $C Y P 2 C 9$, cytochrome P450 family 2 subfamily C member $9 ; H S D 11 B 1$, hydroxysteroid $11-\beta$ dehydrogenase $1 ; H S D 17 B 13$, hydroxysteroid $17-\beta$ dehydrogenase 13 ; $S L C 22 A 1$, solute carrier family 22 member $1 ; C Y P 2 C 8$, cytochrome p450 family 2 subfamily C member 8 ; $A D H 4$, alcohol dehydrogenase 4 (class II), pi polypeptide.

\section{Results}

Processing of DEGs and hub genes. A total of 71 DEGs were obtained from the GSE36376 dataset and the top 10 hub genes were identified. These 10 hub genes included cytochrome P450 family 2 subfamily E member 1 (CYP2E1), tyrosine aminotransferase (TAT), cytochrome $\mathrm{P} 450$ family 2 subfamily A member 6 (CYP2A6), cytochrome $\mathrm{P} 450$ family 8 subfamily B member 1 (CYP8B1), cytochrome $\mathrm{P} 450$ family 2 subfamily $\mathrm{C}$ member 9 (CYP2C9), hydroxysteroid 11- $\beta$ dehydrogenase 1 (HSD11B1), hydroxysteroid 17- $\beta$ dehydrogenase 13 (HSD17B13), solute carrier family 22 member 1 (SLC22A1), cytochrome p450 family 2 subfamily $\mathrm{C}$ member $8(C Y P 2 C 8)$ and alcohol dehydrogenase 4 (class II), pi polypeptide $(A D H 4)$. Detailed results are shown in Table I.

Analysis of hub gene expression, mutation and transcription. Hub gene expression in tumor tissues was downregulated compared with normal tissues in all cases (Fig. 1). However, only CYP2A6, CYP2C8, CYP2E1, HSD17B13 and SLC22A1 had a significant alteration in expression $(\mathrm{P}<0.05)$. Tissue expression data indicated that all of the hub genes were highly 

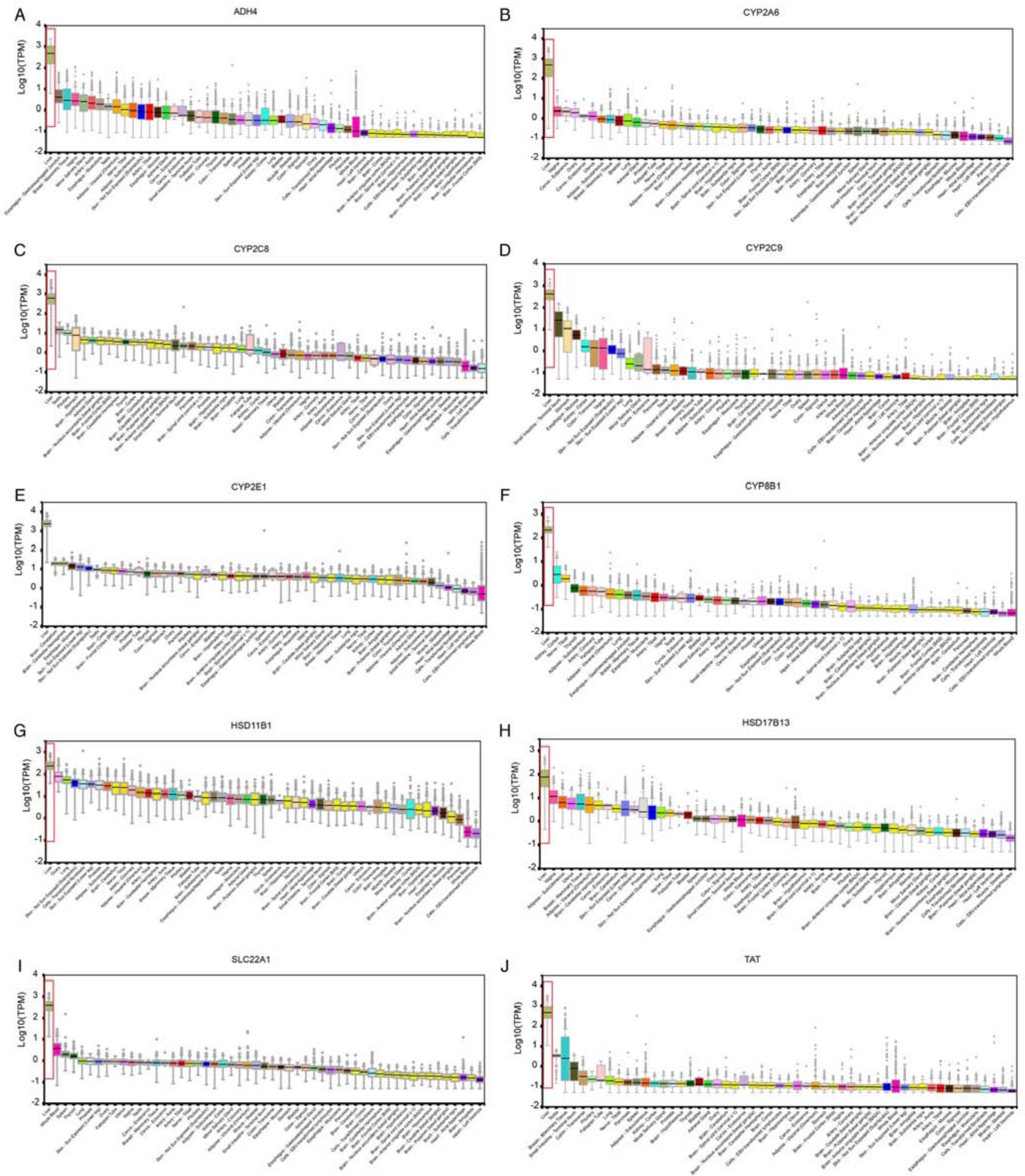

Figure 2. Expression levels of hub genes (A) ADH4, (B) CYP2A6, (C) CYP2C8, (D) CYP2C9, (E) CYP2E1, (F) CYP8B1, (G) HSD11B1, (H) HSD17B13, (I) SLC22A1 and (J) TAT in different organs. High liver expression was noted in all hub genes. TPM, transcripts per million; CYP2E1, cytochrome P450 family 2 subfamily E member 1; TAT, tyrosine aminotransferase; $C Y P 2 A 6$, cytochrome P450 family 2 subfamily A member 6; CYP8B1, cytochrome P450 family 8 subfamily B member $1 ; C Y P 2 C 9$, cytochrome P450 family 2 subfamily C member $9 ; H S D 11 B 1$, hydroxysteroid 11- $\beta$ dehydrogenase $1 ; H S D 17 B 13$, hydroxysteroid 17- $\beta$ dehydrogenase $13 ; S L C 22 A 1$, solute carrier family 22 member $1 ; C Y P 2 C 8$, cytochrome p450 family 2 subfamily C member 8 ; ADH4, alcohol dehydrogenase 4 (class II), pi polypeptide.

expressed in liver tissue (Fig. 2). Mutation analysis of hub genes revealed that mutations were present in different ratios (Fig. 3A). At $11 \%, H S D 11 B 1$ was the most significant in terms of mutation ratio, of which the majority were amplification mutations. Transcriptional analysis (Fig. 3B) demonstrated that all hub genes were differentially transcribed in tumor and normal tissues. Furthermore, normal tissues had consistently high TPM in the 10 hub genes. Detailed results are shown in Fig. 3.

Protein expression data indicated that eight proteins were highly expressed in liver tissue, excluding TAT and CYPSBI 


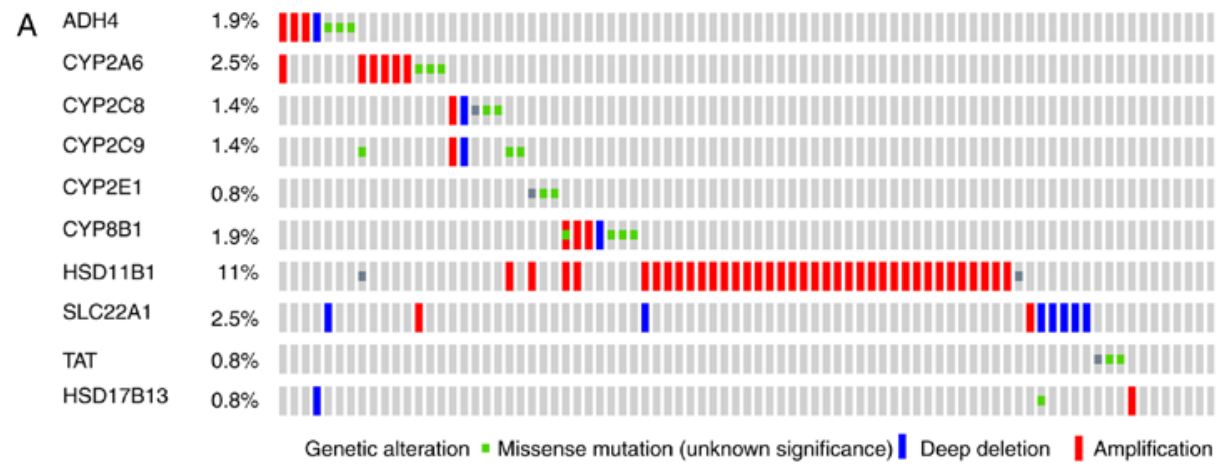

B
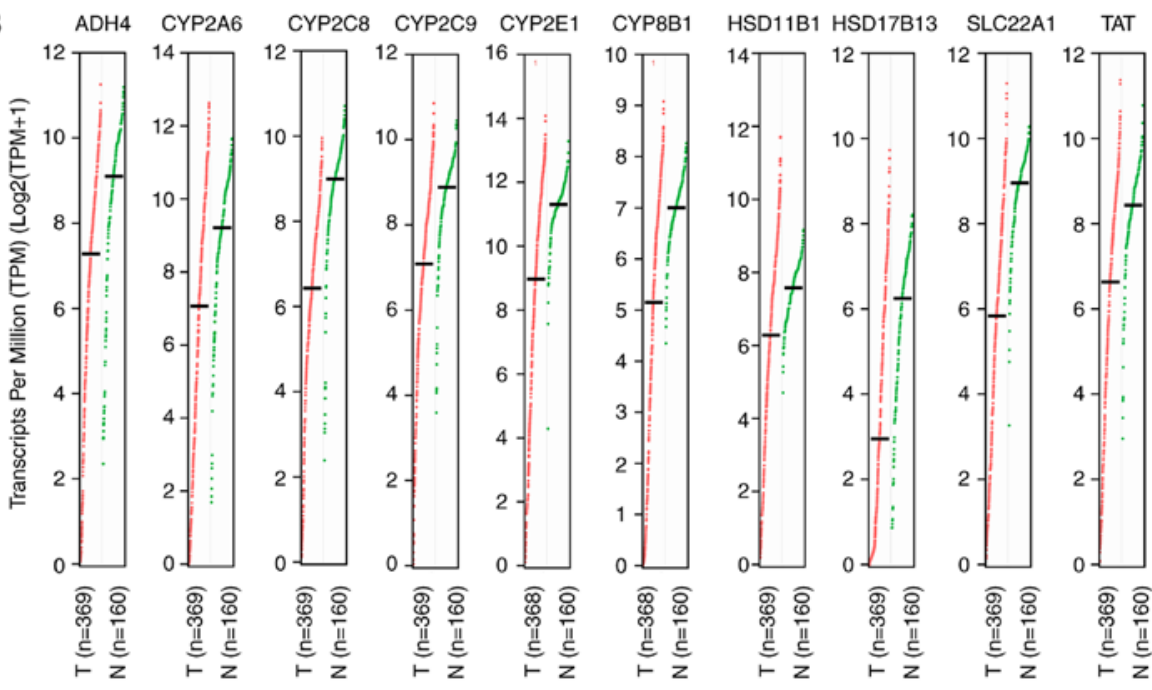

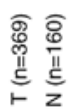
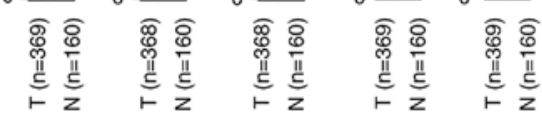

- Normal tissue

Figure 3. Mutational and transcriptional analysis of hub genes. (A) Mutational analysis including missense mutation, deep deletion and amplification of the 10 hub genes. (B) Transcriptional analyses (TPM) of the 10 hub genes in tumor and normal tissues. TPM, transcripts per million; CYP2E1, cytochrome P450 family 2 subfamily E member 1; TAT, tyrosine aminotransferase; CYP2A6, cytochrome P450 family 2 subfamily A member 6; CYP8B1, cytochrome P450 family 8 subfamily B member 1; CYP2C9, cytochrome P450 family 2 subfamily C member $9 ; H S D 11 B 1$, hydroxysteroid 11- $\beta$ dehydrogenase $1 ; H S D 17 B 13$, hydroxysteroid 17- $\beta$ dehydrogenase 13 ; SLC22A1, solute carrier family 22 member 1 ; CYP2C8, cytochrome p450 family 2 subfamily C member 8 ; ADH4, alcohol dehydrogenase 4 (class II), pi polypeptide.

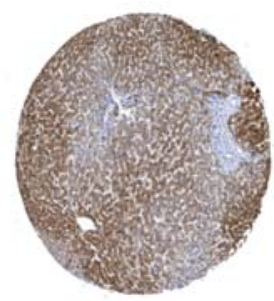

$\mathrm{ADH} 4$

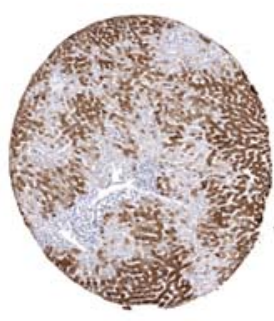

CYP2E1

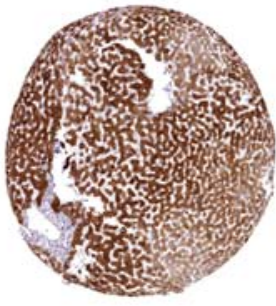

CYP2A6

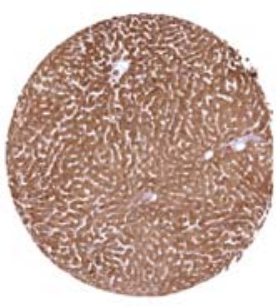

HSD11B1

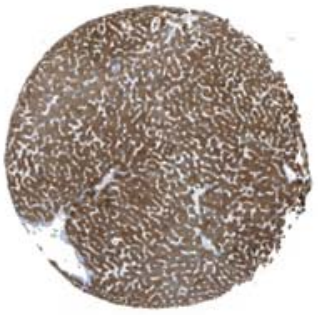

CYP2C8

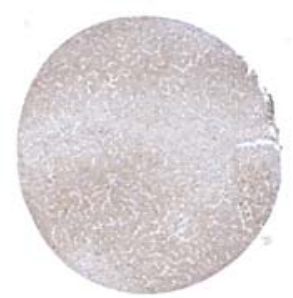

HSD17B13

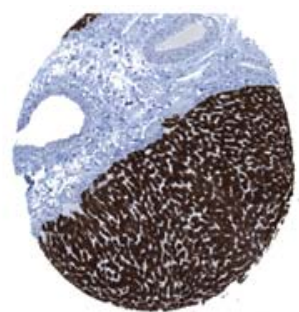

CYP2C9

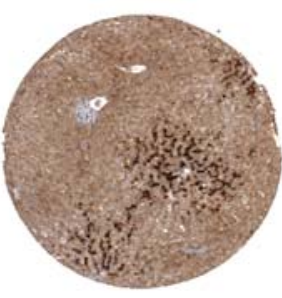

SLC22A1

Figure 4. Immunohistochemistry results of protein expression levels of hub genes $A D H 4, C Y P 2 A 6, C Y P 2 C 8, C Y P 2 C 9, C Y P 2 E 1, H S D 11 B 1, H S D 17 B 13$ and $S L C 22 A 1$ in normal liver tissues. $A D H 4$, alcohol dehydrogenase 4 (class II), pi polypeptide; $C Y P 2 A 6$, cytochrome P450 family 2 subfamily A member 6; CYP2C8, cytochrome p450 family 2 subfamily C member $8 ; C Y P 2 C 9$, cytochrome P450 family 2 subfamily C member $9 ; C Y P 2 E 1$, cytochrome P450 family 2 subfamily E member $1 ; H S D 11 B 1$, hydroxysteroid $11-\beta$ dehydrogenase $1 ; H S D 17 B 13$, hydroxysteroid $17-\beta$ dehydrogenase $13 ;$ SLC22A1, solute carrier family 22 member 1 . 
Table II. Demographic characteristics of HCC patients.

\begin{tabular}{|c|c|c|c|c|c|}
\hline Variables & Patients $(n=360)$ & Number $(\%)$ & MST (days) & HR $(95 \%$ CI) & Log-rank P-value \\
\hline \multicolumn{6}{|l|}{ Race } \\
\hline Asian & 155 & $44(28.4)$ & NA & Ref. & \\
\hline Non-Asian & 196 & $78(39.8)$ & 1,397 & $1.29(0.89-1.87)$ & 0.184 \\
\hline \multicolumn{6}{|l|}{ Sex } \\
\hline Male & 244 & $78(32.0)$ & 2,486 & Ref. & \\
\hline Female & 116 & $48(41.4)$ & 1,560 & $1.21(0.84-1.73)$ & 0.308 \\
\hline \multicolumn{6}{|l|}{ Age (years) } \\
\hline$\leq 61$ & 186 & $59(31.7)$ & 2,116 & Ref. & \\
\hline$>61$ & 171 & $65(38.0)$ & 1,622 & $1.18(0.83-1.69)$ & 0.349 \\
\hline \multicolumn{6}{|l|}{ Tumor stage } \\
\hline I and II & 252 & $66(26.2)$ & 2,532 & Ref. & \\
\hline III and IV & 87 & $48(55.2)$ & 770 & $2.50(1.72-3.63)$ & $<0.0001$ \\
\hline
\end{tabular}

Data were unavailable for race in 9 patients, age in 3 patients and tumor stage in 21 patients. MST, median survival time; HR, hazard ratio; CI, confidence interval; NA, not available; Ref., reference; Tumor stage was determined with the Tumor, Node and Metastasis staging system version 7.
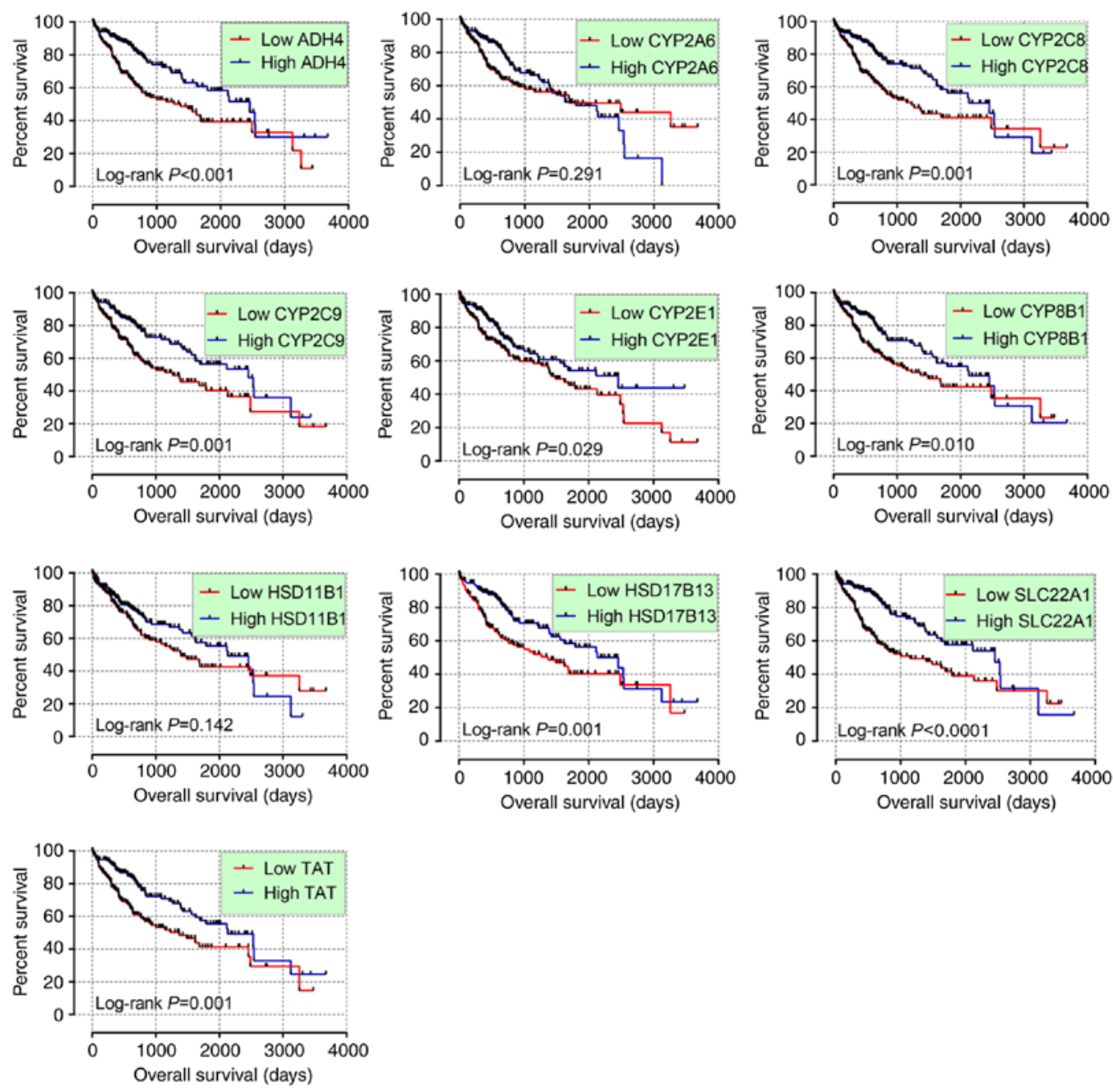

Figure 5. Kaplan-Meier plots of hub genes ADH4, CYP2A6, CYP2C8, CYP2C9, CYP2E1, CYP8B1, HSD11B1, HSD17B13, SLC22A1 and TAT. CYP2E1, cytochrome P450 family 2 subfamily E member 1; TAT, tyrosine aminotransferase; CYP2A6, cytochrome P450 family 2 subfamily A member 6; CYP8B1, cytochrome P450 family 8 subfamily B member 1; CYP2C9, cytochrome P450 family 2 subfamily C member 9; HSD11B1, hydroxysteroid 11- $\beta$ dehydrogenase 1 ; $H S D 17 B 13$, hydroxysteroid $17-\beta$ dehydrogenase $13 ; S L C 22 A 1$, solute carrier family 22 member $1 ; C Y P 2 C 8$, cytochrome p450 family 2 subfamily C member 8 ; $A D H 4$, alcohol dehydrogenase 4 (class II), pi polypeptide. 
Table III. Survival analysis of HCC patient prognosis.

\begin{tabular}{|c|c|c|c|c|c|c|}
\hline $\begin{array}{l}\text { Gene } \\
\text { expression }\end{array}$ & Patients/events & $\begin{array}{l}\text { MST } \\
\text { (days) }\end{array}$ & $\begin{array}{c}\text { Crude } \\
\text { HR }(95 \% \text { CI })\end{array}$ & $\begin{array}{l}\text { Crude } \\
\text { P-value }\end{array}$ & $\begin{array}{c}\text { Adjusted } \\
\text { HR (95\% CI) }\end{array}$ & $\begin{array}{l}\text { Adjusted } \\
\text { P-value }\end{array}$ \\
\hline \multicolumn{7}{|l|}{ ADH4 } \\
\hline Low & $180 / 80$ & 1,372 & Ref. & & Ref. & \\
\hline High & $180 / 46$ & 2,456 & $0.52(0.36-0.75)$ & $<0.001^{\mathrm{a}}$ & $0.55(0.38-0.81)$ & $0.002^{\mathrm{a}}$ \\
\hline \multicolumn{7}{|l|}{ CYP2A6 } \\
\hline Low & $180 / 66$ & 1,694 & Ref. & & Ref. & \\
\hline High & $180 / 60$ & 1,791 & $0.83(0.58-1.18)$ & 0.291 & $0.83(0.57-1.20)$ & 0.321 \\
\hline \multicolumn{7}{|l|}{ CYP2C8 } \\
\hline Low & $180 / 75$ & 1,229 & Ref. & & Ref. & \\
\hline High & $180 / 51$ & 2,456 & $0.560 .39-0.79)$ & $0.001^{\mathrm{a}}$ & $0.56(0.38-0.83)$ & $0.003^{\mathrm{a}}$ \\
\hline \multicolumn{7}{|l|}{ CYP2C9 } \\
\hline Low & $180 / 74$ & 1,271 & Ref. & & Ref. & \\
\hline High & $180 / 52$ & 2,456 & $0.56(0.39-0.80)$ & $0.001^{\mathrm{a}}$ & $0.64(0.43-0.93)$ & $0.020^{\mathrm{a}}$ \\
\hline \multicolumn{7}{|l|}{$C Y P 2 E 1$} \\
\hline Low & $180 / 75$ & 1,490 & Ref. & & Ref. & \\
\hline High & $180 / 51$ & 2,456 & $0.67(0.47-0.96)$ & $0.029^{\mathrm{a}}$ & $0.74(0.51-1.08)$ & 0.119 \\
\hline \multicolumn{7}{|l|}{ CYP $8 B 1$} \\
\hline Low & $180 / 73$ & 1,372 & Ref. & & Ref. & \\
\hline High & $180 / 53$ & 2,131 & $0.63(0.44-0.90)$ & $0.010^{\mathrm{a}}$ & $0.61(0.42-0.89)$ & $0.011^{\mathrm{a}}$ \\
\hline \multicolumn{7}{|l|}{$H S D 11 B 1$} \\
\hline Low & $180 / 71$ & 1,397 & Ref. & & Ref. & \\
\hline High & $180 / 55$ & 2,131 & $0.77(0.54-1.09)$ & 0.142 & $0.81(0.56-1.18)$ & 0.279 \\
\hline \multicolumn{7}{|l|}{$S L C 22 A 1$} \\
\hline Low & $180 / 79$ & 1,149 & Ref. & & Ref. & \\
\hline High & $180 / 47$ & 2,456 & $0.49(0.34-0.70)$ & $<0.0001^{\mathrm{a}}$ & $0.51(0.35-0.75)$ & $0.001^{\mathrm{a}}$ \\
\hline \multicolumn{7}{|l|}{$T A T$} \\
\hline Low & $180 / 74$ & 1,372 & Ref. & & Ref. & \\
\hline High & $180 / 52$ & 2,131 & $0.56(0.39-0.80)$ & $0.001^{\mathrm{a}}$ & $0.53(0.36-0.78)$ & $0.001^{\mathrm{a}}$ \\
\hline \multicolumn{7}{|l|}{$H S D 17 B 13$} \\
\hline Low & $180 / 74$ & 1,372 & Ref. & & Ref. & \\
\hline High & $180 / 52$ & 2,456 & $0.57(0.40-0.81)$ & $0.001^{\mathrm{a}}$ & $0.56(0.39-0.82)$ & $0.003^{\mathrm{a}}$ \\
\hline
\end{tabular}

aP $<0.05$. MST, median survival time; HR, hazard ratio; CI, confidence interval; $C Y P 2 E 1$, cytochrome P450 family 2 subfamily E member 1; $T A T$, tyrosine aminotransferase; $C Y P 2 A 6$, cytochrome P450 family 2 subfamily A member 6 ; $C Y P 8 B 1$, cytochrome P450 family 8 subfamily B member 1; CYP2C9, cytochrome P450 family 2 subfamily C member 9; HSD11B1, hydroxysteroid 11- $\beta$ dehydrogenase 1 ; HSD17B13, hydroxysteroid $17-\beta$ dehydrogenase 13 ; SLC22A1, solute carrier family 22 member $1 ; C Y P 2 C 8$, cytochrome p450 family 2 subfamily C member 8; $A D H 4$, alcohol dehydrogenase 4 (class II), pi polypeptide.

(data not shown; Fig. 4), which was similar to the tissue expression results.

Demographic and clinicopathological characteristics. A total of $360 \mathrm{HCC}$ patients were included in the dataset. Survival analysis indicated that tumor stage showed statistical significance (log-rank $\mathrm{P}<0.0001)$, but all other factors were not significant (log-rank $\mathrm{P}>0.05$; Table II).

Expression levels and survival analysis of hub genes. In the univariate survival analysis, $A D H 4, C Y P 2 C 8, C Y P 2 C 9$,
CYP2E1, CYP8B1, HSD17B13, SLC22A1 and TAT were significant $(\mathrm{P} \leq 0.05$; Table III and Fig. 5). Following adjustment for tumor stage, $A D H 4, C Y P 2 C 8, C Y P 2 C 9, C Y P 8 B 1, S L C 22 A 1$, $T A T$ and $H S D 17 B 13$ were significant $(\mathrm{P} \leq 0.05$; Table III) while CYP2A6, CYP2E1, HSD11B1 were not significant $(\mathrm{P}>0.05)$. All hub genes were significantly different when comparing high and low expression levels $(\mathrm{P}<0.0001$; Fig. 6A).

Stratified analysis of prognosis-associated genes. In the stratification of tumor stage, high expression levels of $C Y P 2 C 8$, CYP2C9, SLC22A1, TAT and HSD17B13 had tumor suppressor 


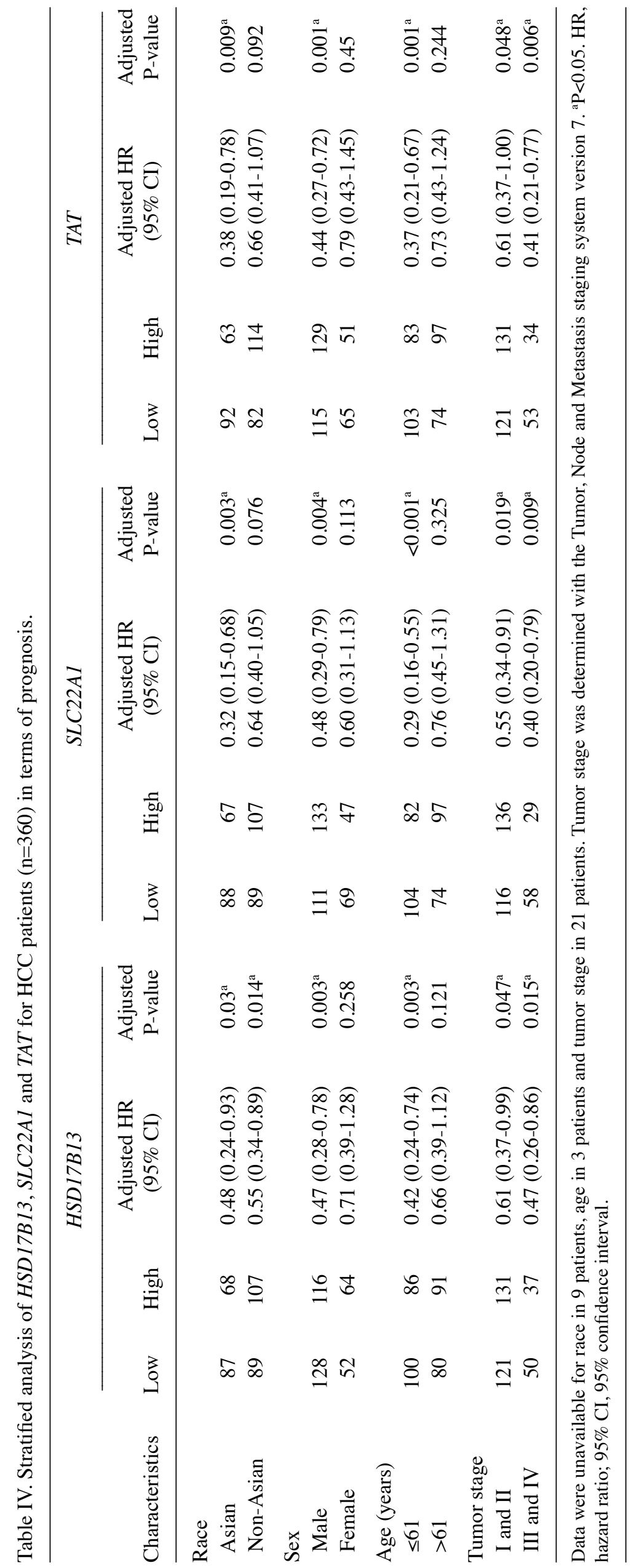




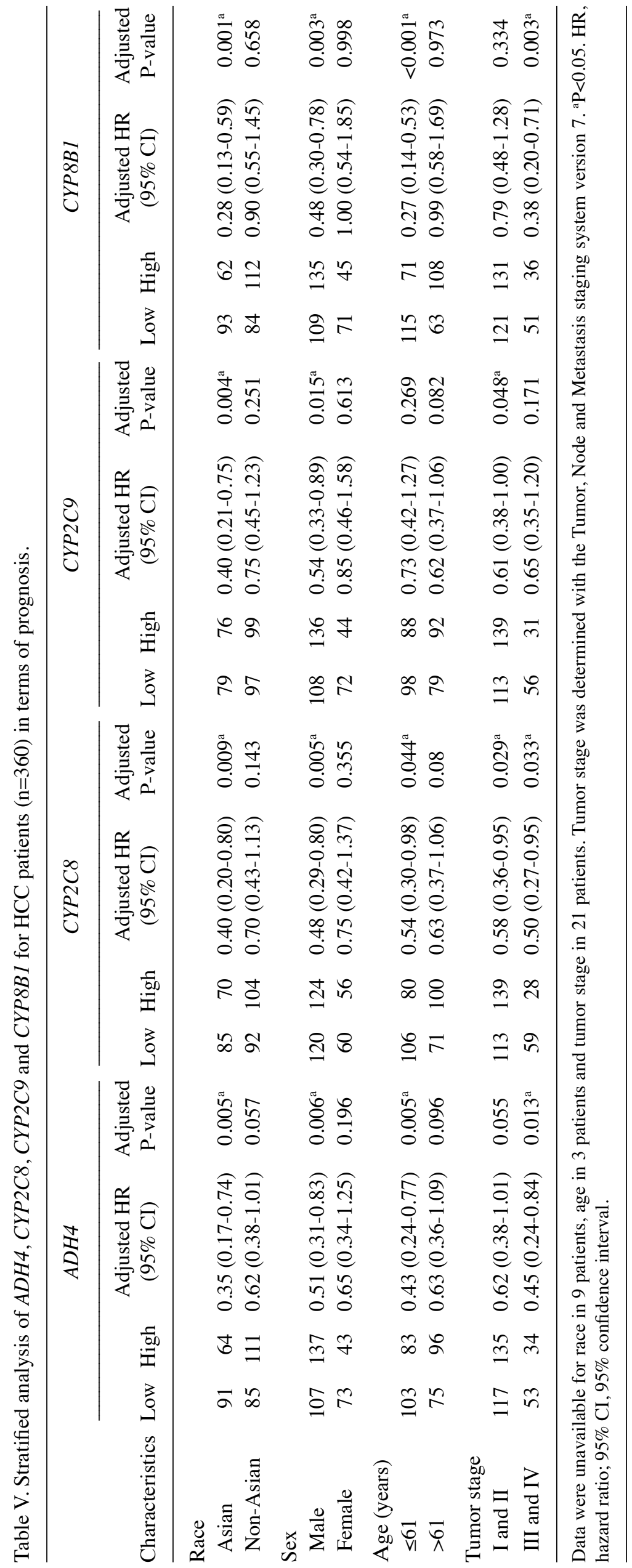



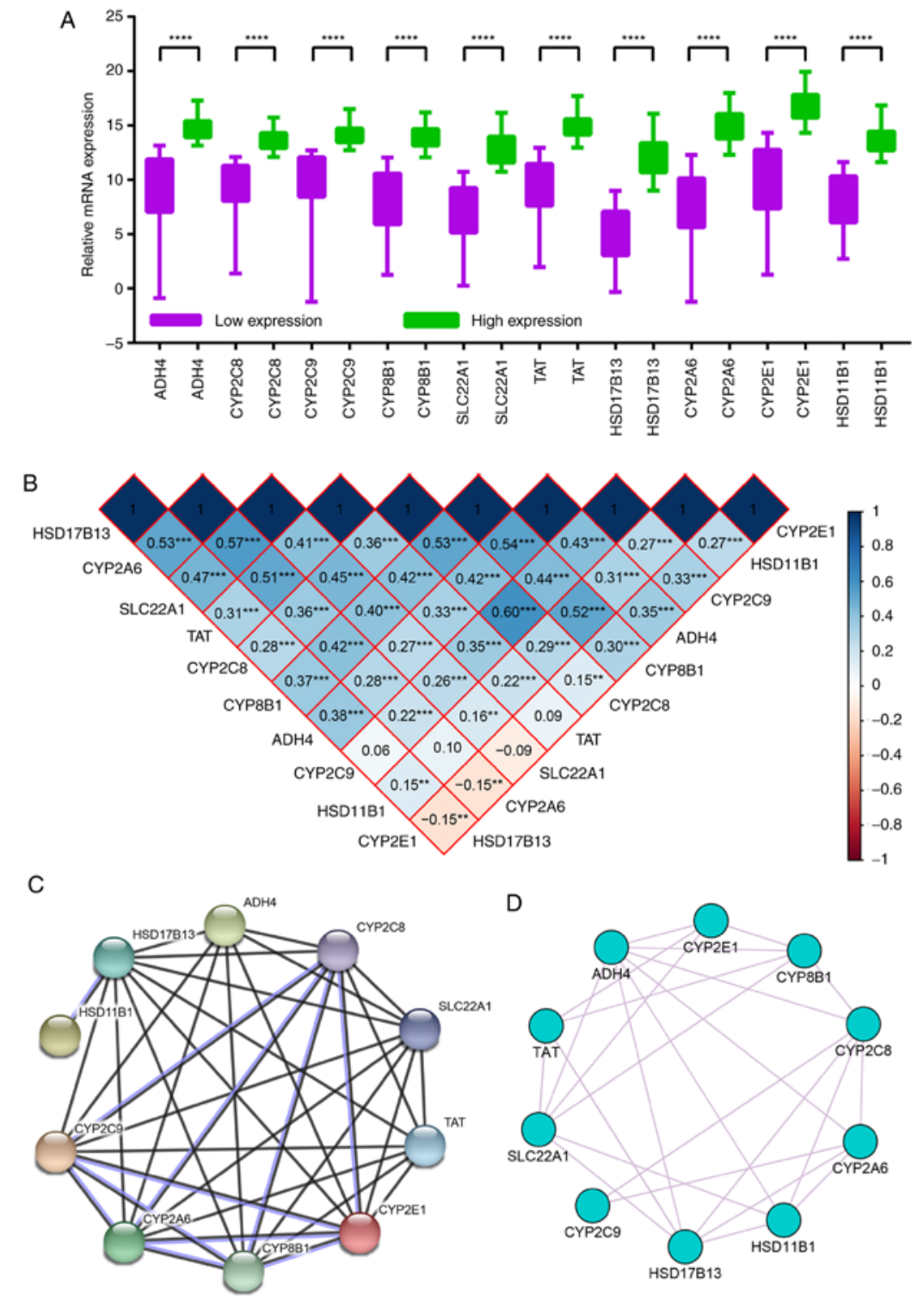

Figure 6. Expression levels, Pearson's correlations and expression network analysis of hub genes. (A) Relative mRNA expression levels in low expression and high expression groups. (B) Pearson correlation analysis of hub genes. Blue indicates positive correlation and red indicates negative correlation. (C) Protein-protein interaction network and (D) Gene-gene co-expression network of hub genes. ${ }^{* * *} \mathrm{P}<0.01,{ }^{* * * *} \mathrm{P}<0.001,{ }^{* * * *} \mathrm{P}<0.0001$. CYP2E1, cytochrome $\mathrm{P} 450$ family 2 subfamily E member 1; TAT, tyrosine aminotransferase; CYP2A6, cytochrome P450 family 2 subfamily A member 6; CYP8B1, cytochrome P450 family 8 subfamily B member $1 ; C Y P 2 C 9$, cytochrome P450 family 2 subfamily C member $9 ; H S D 11 B 1$, hydroxysteroid $11-\beta$ dehydrogenase $1 ; H S D 17 B 13$, hydroxysteroid 17- $\beta$ dehydrogenase 13; SLC22A1, solute carrier family 22 member 1; CYP2C8, cytochrome p450 family 2 subfamily C member 8; $A D H 4$, alcohol dehydrogenase 4 (class II), pi polypeptide.

roles in stages I and II $(\mathrm{P} \leq 0.05)$ while high expression levels of ADH4, CYP2C8, CYP8B1, SLC22A1, TAT and HSD17B13 had tumor suppressor roles in stages III and IV $(\mathrm{P} \leq 0.05)$. Detailed results are presented in Tables IV and V.

Hub gene co-expression and Pearson correlation analysis. The majority of hub genes showed significant Pearson correlations with other genes. For example, $C Y P 2 E 1$ was positively correlated with $C Y P 2 C 8, C Y P 2 C 9, C Y P 8 B 1, A D H 4$ and $H S D 11 B 1$, and negatively correlated with $C Y P 2 A 6$ and $H S D 17 B 13$. Detailed results are presented in Fig. 6B.

In the PPI network, most of the hub genes exhibited complicated interactive co-expression relationships, with the exception of HSD11B1, which was co-expressed with HSD17B13 alone (Fig. 6C). In the gene-gene interaction network, each gene was co-expressed with at least two other genes (Fig. 6D).

Risk score model and nomogram construction. A risk score model was constructed using the aforementioned formula, which contained risk score ranking, survival status and heat maps of gene expressions (Fig. 7A). The Kaplan-Meier plot revealed that the percent survival difference between the low and high risk groups was significant (Fig. 7B). ROC curves were then constructed to evaluate the prognostic values of the model. In the 1-5 year ROC curves, all AUCs were above 0.6 (Fig. 7C), which shows that this model was useful for prognosis prediction. In the comparison of high and low risk score groups, all of the comparisons showed significant P-values (all $\mathrm{P}<0.001$; Fig. 7D). 

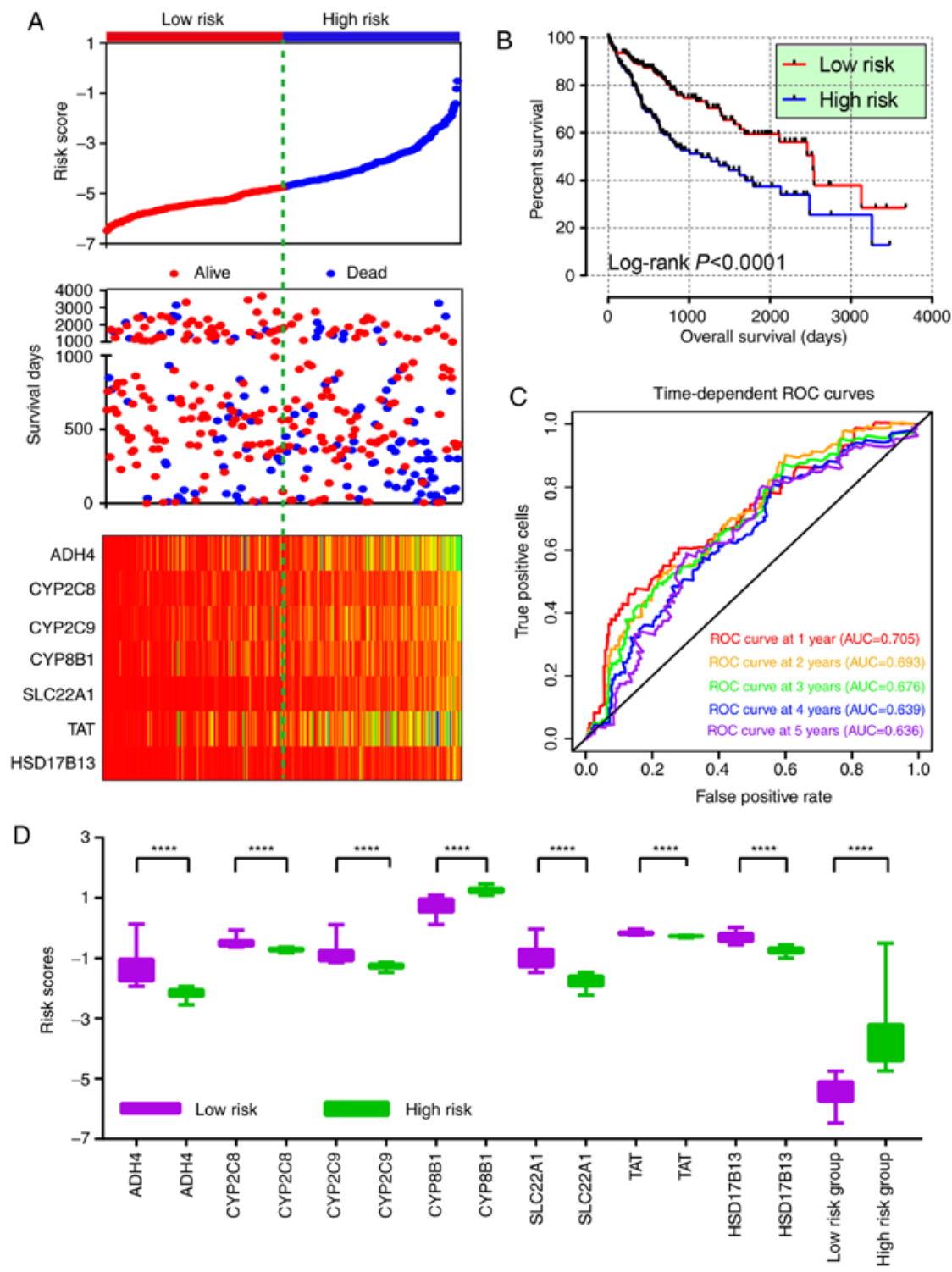

Figure 7. Risk score model, survival plot, ROC curves and boxplot. (A) Risk score model plot including risk score ranking, survival status and heatmap. (B) Kaplan-Meier plot of the risk score model. (C) ROC curves for 1-, 2-, 3-, 4- and 5-year survival rates from the risk score model. (D) Boxplot of risk score groups. ${ }^{* * * * *} \mathrm{P}<0.0001$. ROC, receiver operating characteristic; TAT, tyrosine aminotransferase; CYP8B1, cytochrome P450 family 8 subfamily B member 1 ; CYP2C9, cytochrome $\mathrm{P} 450$ family 2 subfamily C member $9 ; H S D 17 B 13$, hydroxysteroid $17-\beta$ dehydrogenase $13 ; S L C 22 A 1$, solute carrier family 22 member 1 ; CYP2C8, cytochrome p450 family 2 subfamily $\mathrm{C}$ member $8 ; A D H 4$, alcohol dehydrogenase 4 (class II), pi polypeptide.

The contributions of each factor were present in the nomogram (Fig. 8). In detail, tumor stages III and IV showed the maximum 100 points. Unlike the other genes, high expression levels of $C Y P 8 B 1$ had a high number of points. High points typically indicated low survival probability at 1,3 and 5 years. As expected, there was a high probability of survival prediction at 1 year compared with 5 years.

Hub genes enrichment analysis. GO analysis revealed that genes were significantly enriched in the terms such as 'oxidation-reduction process', the 'epoxygenase P450 pathway', 'metbolism of xenobiotics by cytochrome P450', 'chemical carcinogenesis', 'drug metabolic processes' and 'organelle membranes' (Fig. 9).

BP terms, including 'exogenous drug catabolic process', 'drug catabolic process', 'secondary metabolic process' and 'oxidation reduction', were significantly enriched (Fig. 10). In
CC terms, 'subsynaptic reticulum', 'endoplasmic reticulum', 'microsome' and 'vesicular fraction', were enriched (Fig. 11). 'Oxygen binding,, 'iron ion binding', 'heme binding', 'electron carrier activity' and 'oxidoreductase activity', were enriched in terms of MF (Fig. 12).

\section{Discussion}

In the present study, DEGs were analyzed in microarrays to identify hub genes. The top 10 hub genes in the GSE36376 dataset were examined for their prognostic prediction value in HCC. A total of seven genes, including $A D H 4, C Y P 2 C 8$, CYP2C9, CYP8B1, SLC22A1, TAT and HSD17B13, were identified as potential prognostic biomarkers. In addition, high expression levels of these hub genes were associated with tumor suppressing roles in HCC. Stratified analysis of clinical factors further revealed their prognostic values in subgroups. 


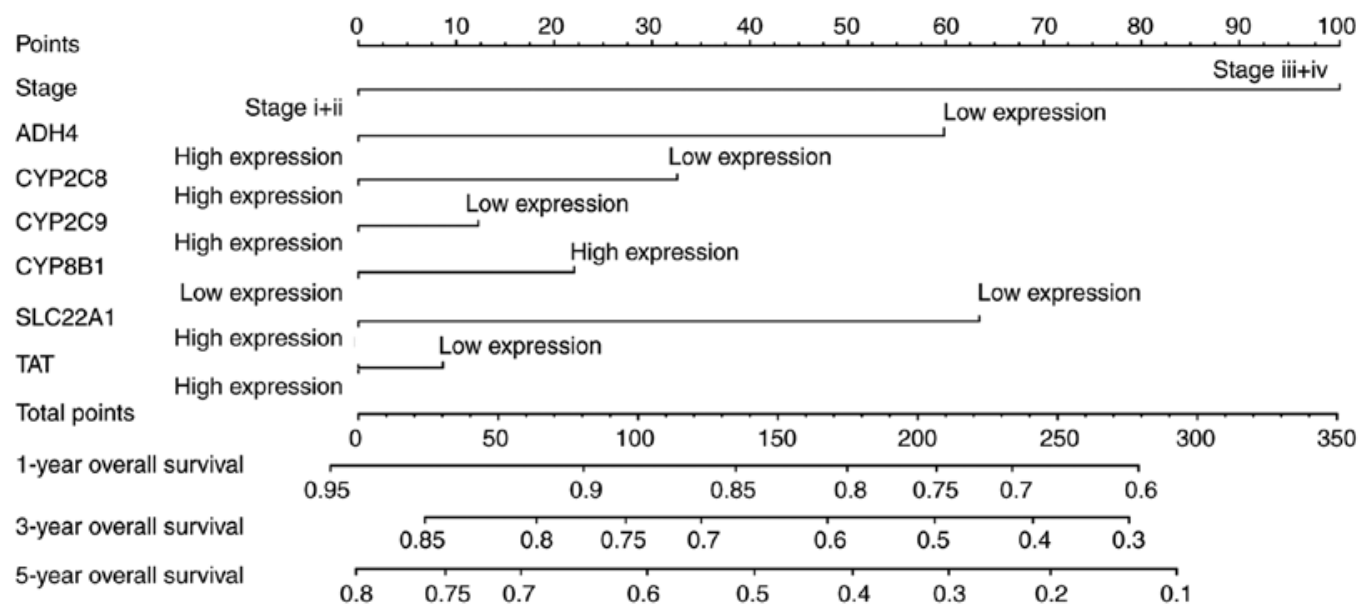

Figure 8. Nomogram for predicting HCC prognosis. TAT, tyrosine aminotransferase; $C Y P 2 C 8$, cytochrome p450 family 2 subfamily $\mathrm{C}$ member 8 ; $C Y P 2 C 9$, cytochrome $\mathrm{P} 450$ family 2 subfamily $\mathrm{C}$ member $9 ; C Y P 2 C 8$, cytochrome p450 family 2 subfamily C member 8 ; $C Y P 8 B 1$, cytochrome P450 family 8 subfamily B member 1; SLC22A1, solute carrier family 22 member 1; $A D H 4$, alcohol dehydrogenase 4 (class II), pi polypeptide.

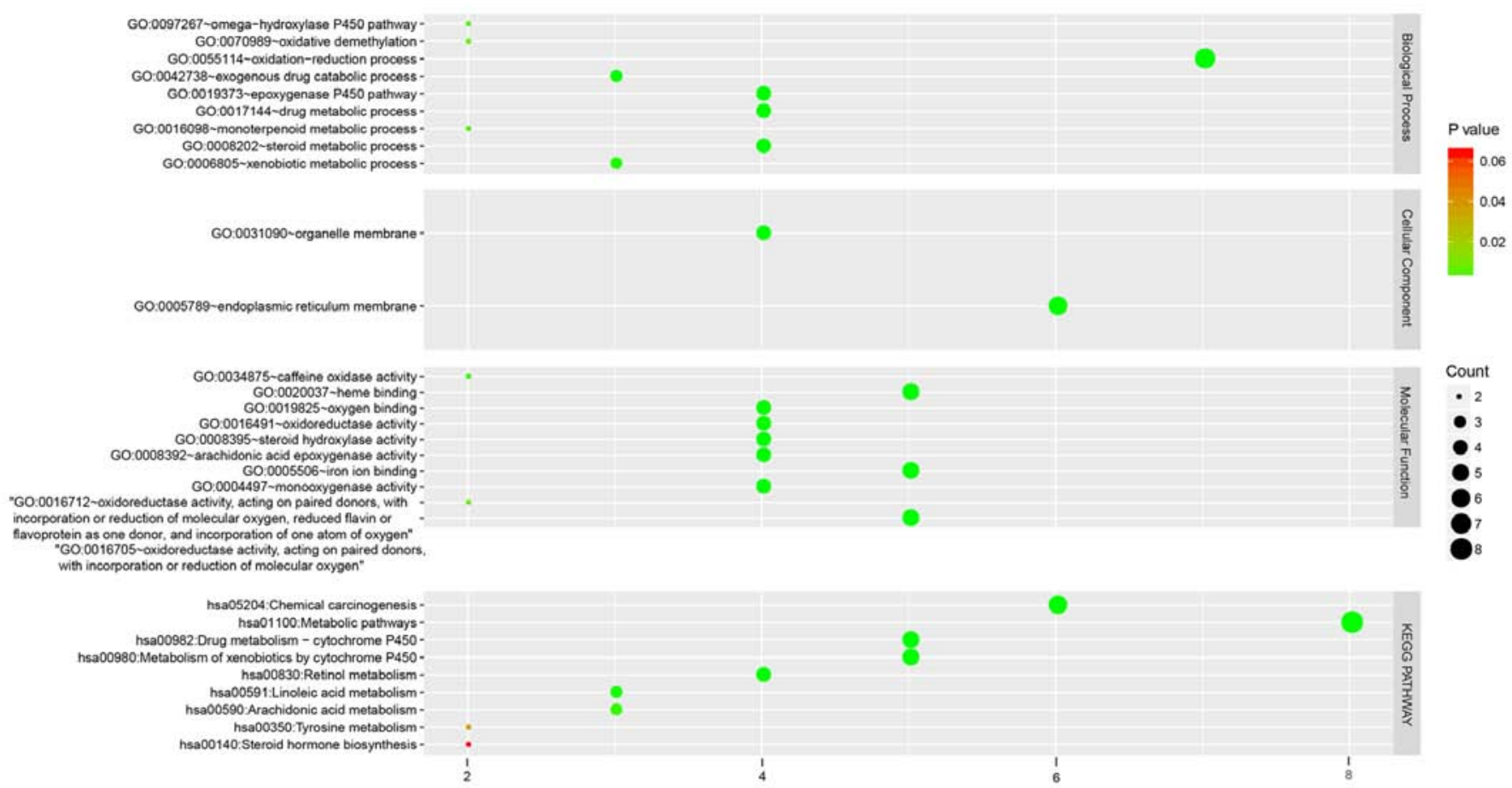

Figure 9. Enriched Gene Ontology and KEGG pathways of hub genes. Genes were analyzed in terms of biological process, cellular component and molecular function. Significantly enriched pathways were identified in the KEGG pathway analysis. KEGG, Kyoto Encyclopedia of Genes and Genomes.

A risk score model for patient survival was constructed and evaluated, which confirmed its value for assessing prognosis. A nomogram was created to identify the degree of the contribution made by each factor. Enrichment analysis of the hub genes highlighted the metabolic pathways and biological processes that the hub genes were involved in, which may provide clues into the exact mechanisms of HCC development.

Valuable data in gene microarrays may be lost due to potentially unpredictable problems with the samples when the results of a single piece of research are analyzed (27). Furthermore, using a Student's t-test to analyze microarray data has several limitations (27). Small sample sizes may lead to unreliable variance estimation, leading to a high false-positive rate, while some significant and reliable differences in expression may be missed (28). However, in the present study, analyzing microarray data from a study with a large sample size, allowed the acquisition of potentially useful information for further analysis. In total, 433 samples from the GSE36376 dataset were analyzed to obtain DEGs, in order to determine potential serum biomarkers for HCC diagnosis and prognosis. Focused on an Asian population, the present study also searched for DEGs using the GEO2R online resource. The top 10 hub genes in these DEGs were selected for further analysis, and seven of these hub genes, $A D H 4, C Y P 2 C 8, C Y P 2 C 9, C Y P 8 B 1$, $S L C 22 A 1, T A T$ and $H S D 17 B 13$, were confirmed to have prognostic value in HCC. 


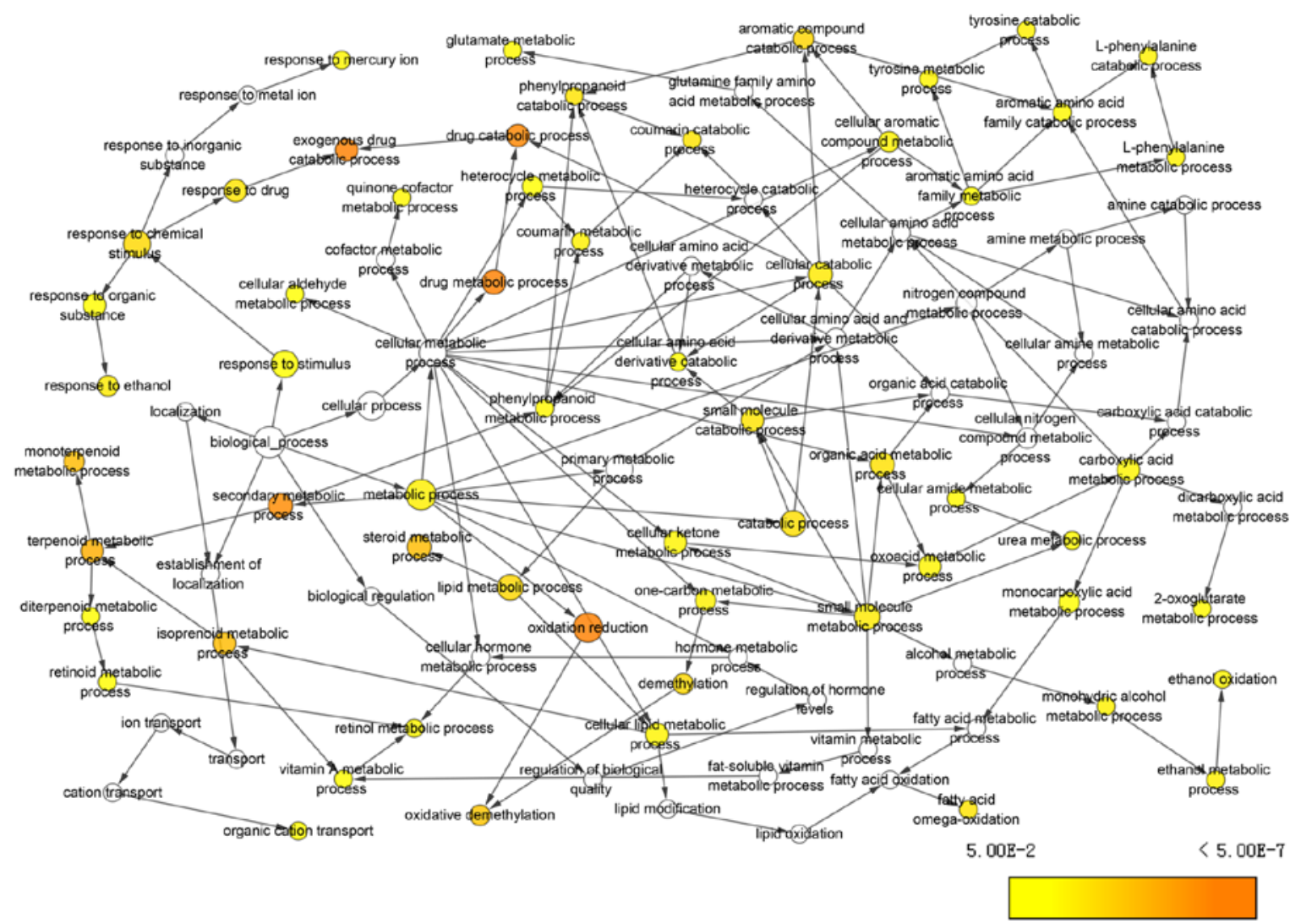

Figure 10. Enriched BP interaction network of hub genes. BP terms, including 'exogenous drug catabolic process', 'drug catabolic process', 'secondary metabolic process' and 'oxidation reduction', were significantly enriched. BP, biological process.

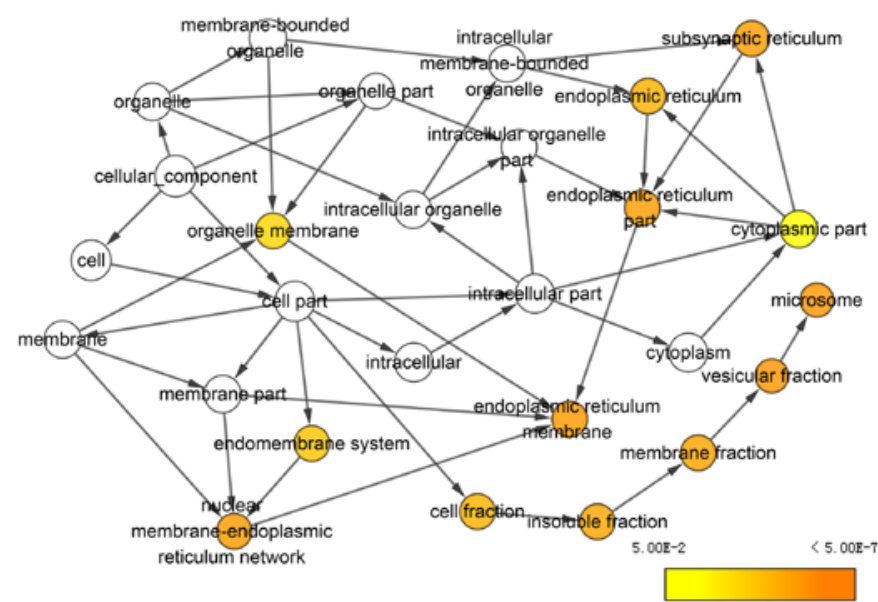

Figure 11. Enriched CC interaction network of hub genes. In CC terms, 'subsynaptic reticulum', 'endoplasmic reticulum', 'microsome' and 'vesicular fraction', were enriched. CC, cellular component.

The human ADH4 enzyme is encoded by the ADH4 gene, which maps to $4 \mathrm{q} 22$ within the ADH gene cluster (29). Previous studies have revealed that a $A D H 4$ gene variant confers risk for alcohol dependence (AD) and related traits in European Americans and African Americans (29). Edenberg et al (30) reported that 16 single nucleotide polymorphisms (SNP) of $A D H 4$, including rs2226896, are associated with $\mathrm{AD}$, in an independent collaborative study on the genetics of alcoholism. Edenberg et al (31) showed that ADH4 promoter variant $-75 \mathrm{~A} / \mathrm{C}$ (rs800759), which could alter ADH4 enzyme expression levels significantly, as well as the 159A/G variant were significantly linked to AD in European Americans and African Americans in a Brazilian population (31). Previous studies have reported that $A D H 4$ may be associated with cluster headaches and personality traits such as agreeableness and extraversion $(32,33)$. In addition, polymorphisms in the $A D H 4$ gene are associated with a decreased risk of ovarian cancer (34) and an increased risk of upper aerodigestive tract cancer (35), which suggests that the $A D H 4$ may be involved in tumorigenesis. Wei et al (36) found that $A D H 4$ mRNA expression in HCC is significantly lower than that in non-cancerous tissue, and ADH4 protein expression is also reduced in HCC, which indicates that ADH4 may serve as a tumor suppressor. These findings are consistent with the results of the present study, where ADH4 was identified as a potential prognostic biomarker for HCC.

The CYP2 family contains many subfamilies, including CYP2A, CYP2B, CYP2C, CYP2D, CYP2E and CYP2F (37). CYP2C 8 and $C Y P 2 C 9$ are members of the CYP2C subfamily that are localized in a single gene locus on chromosome $10(38,39)$. CYP2C8 shares sequence homology with CYP2C9, that metabolizes several drugs including analgesics (40), antidiabetic and cholesterol-lowering drugs (41). CYP2C9 metabolizes the majority of angiotensin II type 1 receptor blockers (42) and neurological drugs (43). In addition, CYP2C8 has been associated with an increased risk of essential hypertension and coronary artery disease in Bulgarian patients (44), anemia (45), vascular inflammatory disease (46) 


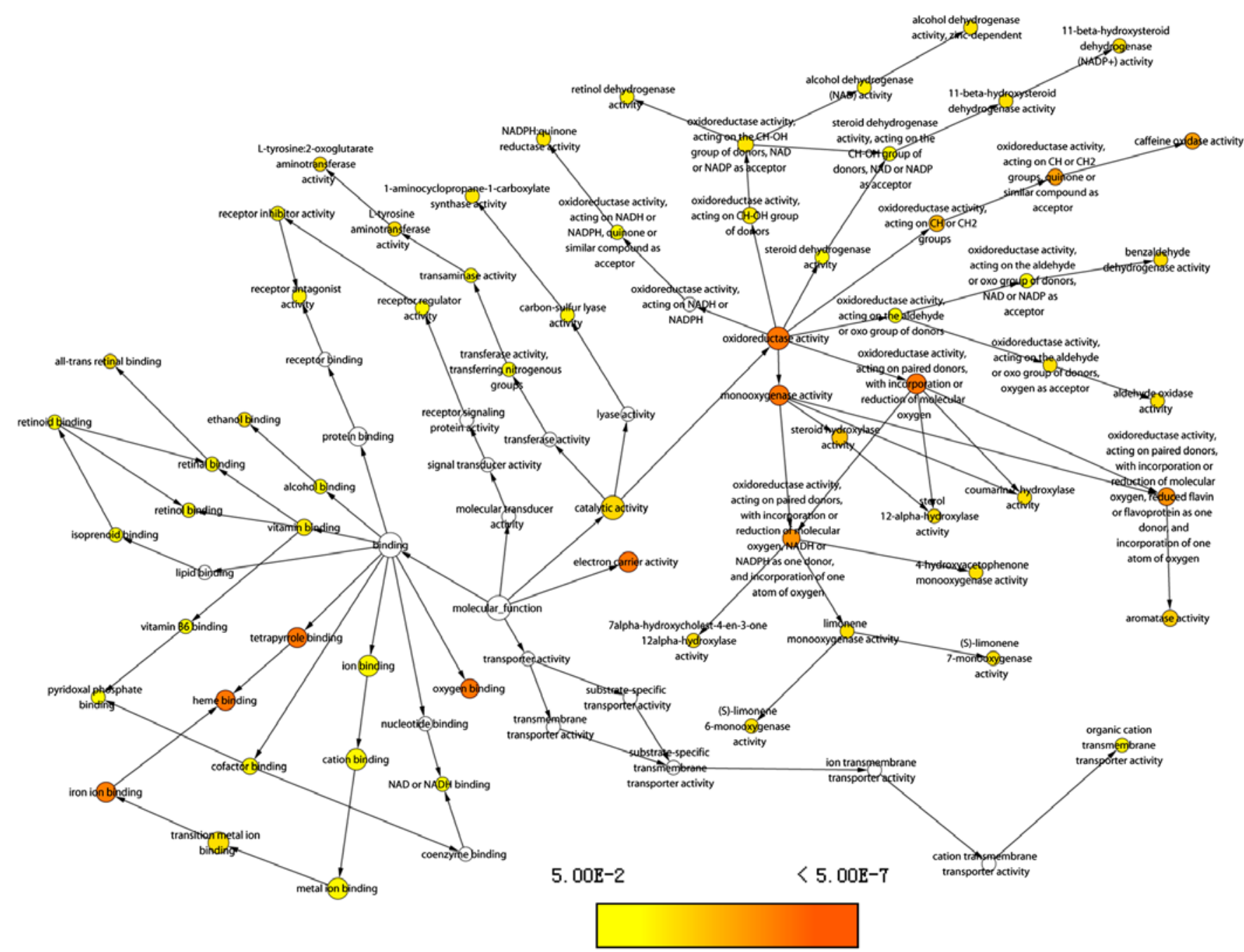

Figure 12. Enriched MF interaction network of hub genes.'Oxygen binding', 'iron ion binding', 'heme binding', 'electron carrier activity' and 'oxidoreductase activity', were enriched in terms of MF. MF, molecular function.

and breast cancer (47). It has been reported that CYP2C9 downregulation by miR-128-3p is associated with HCC (48). In addition, we have previously reported that analysis of CYP2C8 and CYP2C9 expression in combination is better than analyzing them in isolation (37).

CYP8B1 is predominantly expressed in hepatocytes in a homogenous pattern (49) and is involved in bile acid synthesis of bile acids (50). Overexpression of CYP8B1 alone or in combination with CYP7A1, but not of CYP7A1 alone, reverses obeticholic acid-induced alterations in bile acid levels (taurocholic acid), bile acid composition (taurocholic acid and $\alpha / \beta$-muricholic acids) and cholesterol absorption (51). The SNP rs3732860 in the 3'-untranslated region of the CYP8B1 gene is linked to gallstone disease risk in the Chinese Han population $(52,53)$. However, the function of CYP8B1 in cancer remains elusive. The present study indicated that CYP8B1 may serve as a potential biomarker for HCC, and may be involved in tumor initiation and development.

SLC22Al has the ability to encode solute carrier family 22 member 1 , which is not only an uptake transporter but also has a predictive value for the molecular response to imatinib mesylate therapy (54). Patients who experience a major molecular response have higher SLC22Al expression compared with those without a major molecular response (55). SLC22A1-ABCB1 haplotype profiles can predict imatinib pharmacokinetics in Asian patients with chronic myeloid leukemia (56). Indirect SLC22Al gene upregulation by dexamethasone may be caused by glucocorticoid receptor-induced hepatocyte nuclear factor- $4 \alpha$ expression in primary human hepatocytes, but not in hepatocyte-derived tumor cell lines (57). HCC and cholangiocarcinoma development is typically accompanied by decreased SLC22A1 expression, which may significantly alter the ability of sorafenib to reach active intracellular concentrations in these tumors (58). Downregulated SLC22A1 expression is associated with tumor progression and decreased survival in patients with cholangiocellular carcinoma (59). However, to the best of our knowledge, the relationship between SLC22A1 and HCC patient prognosis has not been reported. The present study demonstrated that SLC22A1 may be a predictive biomarker for HCC.

TAT is associated with the catalyzing the transamination of tyrosine and other aromatic amino acids and plays a role in recovery from tyrosinemia type II, hepatitis and hepatic carcinoma (60). Deficiency of TAT causes marked hypertyrosinemia, which leads to painful palmoplantar hyperkeratosis, pseudodendritic keratitis, and variable mental retardation (61). Recurrent mutation of the TAT gene has been reported in those 
affected by Richner-Hanhart syndrome (62). Fu et al (63) reported that downregulation of TAT at a frequently deleted region, 16q22, contributes to the pathogenesis of $\mathrm{HCC}$, and it was demonstrated that TAT is a novel tumor suppressor gene. This finding is consistent with the results of the present study, and may be used as an effective serum biomarker for HCC.

Su et al (64) reported that $H S D 17 B 13$ is upregulated in the livers of patients with non-alcoholic fatty liver disease. HSD17B13 expression is localized to liquid droplets (65). In addition, Chen et al (66) reported that HSD17B13 is downregulated in $\mathrm{HCC}$, and has a tumor suppressor role via inhibition of HCC progression and recurrence (66). This finding is in accordance with the results of the present study, where it was concluded that HSD17B13 may serve as a potential predictive biomarker for HCC.

In regards to metabolic pathways, our previous study demonstrated that the CYP2C subfamily members are involved in chemical carcinogenesis (37). The formation of DNA adducts, dG-C8-IQ, dG-N-IQ, dG-C8-MeIQx and dG-N-MeIQx, may induce liver, colon lung and breast cancer tumorigenesis (37). The present study found that the identified hub genes were also enriched in chemical carcinogenesis. Additionally, gene were enriched in 'drug metabolism-cytochrome P450', 'metabolism of xenobiotics by cytochrome P450', 'retinol metabolism', 'linoleic acid metabolism', 'arachidonic acid metabolism', 'tyrosine metabolism', and 'steroid hormone biosynthesis'. These metabolic processes and pathways provide evidence that the hub genes may be involved in hepatocarcinogenesis.

There are some limitations to the present study. First, larger samples that include other populations are required to validate the findings of the present study. Second, an increased number of valid clinical factors, such as race, drinking status, smoking status, cirrhosis, Barcelona-Clinic liver cancer staging, hepatitis infection status, antiviral therapy, $\alpha$-fetoprotein levels and microvascular invasion, should be included in the analysis. Third, functional validation in a well-designed clinical trial is required to examine the biological behavior of prognosis-associated genes on HCC initiation and progression. As the present study explored the potential prognostic biomarkers for HCC, the identification and clinical significance of targeted drugs was not investigated in the present study. Thus, it is crucial to focus future studies on these topics.

The present study indicated that low gene expression of $A D H 4, C Y P 2 C 8, C Y P 2 C 9, C Y P 8 B 1, S L C 22 A 1, T A T$ and $H S D 17 B 13$ are predictors of poor prognosis in HCC. Further functional trials and identification of targeted drugs for these hub genes is warranted to determine clinical application. In detail, trials in vivo and in vitro should be conducted to explore biological behavior, such as invasion, metastasis and proliferation ability. Then, the influence potential drugs on their target genes should be validated, to determine whether targeted overexpression of these genes improve HCC prognosis.

\section{Acknowledgements}

The authors would like to acknowledge the laboratory equipment and platform support provided by the Key Laboratory of Early Prevention and Treatment for Regional High-Incidence-Tumor (Guangxi Medical University; Ministry of Education, Nanning, China). The authors would also like to acknowledge the helpful comments on this article received from our reviewers.

\section{Funding}

The present study was supported in part by the National Nature Science Foundation of China (grant nos. 81560535, 81072321, 30760243, 30460143 and 30560133), the 2009 Program for New Century Excellent Talents in University, Guangxi Nature Sciences Foundation (grant no. GuiKeGong 1104003A-7), the Guangxi Health Ministry Medicine Grant (grant no. Key-Scientific Research-Grant Z201018), the Self-Raised Scientific Research Fund of the Health and Family Planning Commission of Guangxi Zhuang Autonomous Region (grant no. Z2016318), the Basic Ability Improvement Project for Middle-aged and Young Teachers in Guangxi Colleges and Universities (grant no. 2018KY0110), Innovation Project of Guangxi Graduate Education (grant no. JGY2018037) and the Research Institute of Innovative Think-tank in Guangxi Medical University (The gene-environment interaction in hepatocarcinogenesis in Guangxi HCCs and its translational applications in the HCC prevention).

\section{Availability of data and materials}

The datasets analyzed during the current study are available from the corresponding author on reasonable request.

\section{Authors' contributions}

XW and TP designed the study. XL, CY, TY, LY, CH, GZ, KH, XZe, ZL, XZh, WQ, HS, XY and TP conducted the study and analyzed the data. XW wrote the manuscript and TP revised the manuscript. All authors read and approved the manuscript and agree to be accountable for all aspects of the research in ensuring that the accuracy or integrity of any part of the work are appropriately investigated and resolved.

\section{Ethics approval and consent to participate}

Not applicable.

\section{Patient consent for publication}

Not applicable.

\section{Competing interests}

The authors declare that they have no competing interests.

\section{References}

1. Torre LA, Bray F, Siegel RL, Ferlay J, Lortet-Tieulent J and Jemal A: Global cancer statistics, 2012. CA Cancer J Clin 65: 87-108, 2015.

2. Kolonel LN and Wilkens LR: Migrant studies. In: Cancer Epidemiology and Prevention. Schottenfeld D and Fraumeni JF, Jr (eds). 3rd edition. Oxford University Press, Inc., New York, NY, pp189-201, 2006

3. Kgatle MM, Setshedi M and Hairwadzi HN: Hepatoepigenetic alterations in viral and nonviral-induced hepatocellular carcinoma. Biomed Res Int 2016: 3956485, 2016. 
4. Marotta F, Vangieri B, Cecere A and Gattoni A: The pathogenesis of hepatocellular carcinoma is multifactorial event. Novel immunological treatment in prospect. Clin Ter 155: 187-199, 2004.

5. Coleman WB: Mechanisms of human hepatocarcinogenesis. Curr Mol Med 3: 573-388, 2003.

6. Dominguez-Malagón H and Gaytan-Graham S: Hepatocellular carcinoma: An update. Ultrastruct Pathol 25: 497-516, 2001.

7. Chen G, Wang D, Zhao X, Cao J, Zhao Y, Wang F, Bai J, Luo D and Li L: miR-155-5p modulates malignant behaviors of hepatocellular carcinoma by directly targeting CTHRC1 and indirectly regulating GSK-3 $\beta$-involved Wnt $/ \beta$-catenin signaling. Cancer Cell Int 17: 118, 2017.

8. Balogh J, Victor D III, Asham EH, Burroughs SG, Boktour M, Saharia A, Li X, Ghobrial RM and Monsour HP Jr: Hepatocellular carcinoma: A review. J Hepatocell Carcinoma 3: 41-53, 2016.

9. Tien AJ, Chien CY, Chen YH, Lin LC and Chien CT: fruiting bodies of antrodia cinnamomea and its active triterpenoid, antcin $\mathrm{K}$, ameliorates $\mathrm{N}$-nitrosodiethylamine-induced hepatic inflammation, fibrosis and carcinogenesis in rats. Am J Chin Med 45: 173-198, 2017.

10. Quintavalle C, Hindupur SK, Quagliata L, Pallante P, Nigro C, Condorelli G, Andersen JB, Tagscherer KE, Roth W, Beguinot F, et al: Phosphoprotein enriched in diabetes (PED/PEA15) promotes migration in hepatocellular carcinoma and confers resistance to sorafenib. Cell Death Dis 8: e3138, 2017.

11. Xu G and Dang C: CMTM5 is downregulated and suppresses tumour growth in hepatocellular carcinoma through regulating PI3K-AKT signalling. Cancer Cell Int 17: 113, 2017.

12. Cao MQ, You AB, Zhu XD, Zhang W, Zhang YY, Zhang SZ, Zhang KW, Cai H, Shi WK, Li XL, et al: miR-182-5p promotes hepatocellular carcinoma progression by repressing FOXO3a J Hematol Oncol 11: 12, 2018.

13. Maass T, Sfakianakis I, Staib F, Krupp M, Galle PR and Teufel A: Microarray-based gene expression analysis of hepatocellular carcinoma. Curr Genomics 11: 261-268, 2010.

14. Fu Q, Yang F, Zhao J, Yang X, Xiang T, Huai G, Zhang J, Wei L, Deng $S$ and Yang H: Bioinformatical identification of key pathways and genes in human hepatocellular carcinoma after CSN5 depletion. Cell Signal 49: 79-86, 2018.

15. Huang da W, Sherman BT and Lempicki RA: Bioinformatics enrichment tools: Paths toward the comprehensive functional analysis of large gene lists. Nucleic Acids Res 37: 1-13, 2009.

16. Davis S and Meltzer PS: GEOquery: A bridge between the gene expression omnibus (GEO) and BioConductor. Bioinformatics 23: $1846-1847,2007$.

17. Lim HY, Sohn I, Deng S, Lee J, Jung SH, Mao M, Xu J, Wang K, Shi S, Joh JW, et al: Prediction of disease-free survival in hepatocellular carcinoma by gene expression profiling. Ann Surg Oncol 20: 3747-3753, 2013

18. Shannon P, Markiel A, Ozier O, Baliga NS, Wang JT, Ramage D, Amin N, Schwikowski B and Ideker T: Cytoscape: A software environment for integrated models of biomolecular interaction networks. Genome Res 13: 2498-2504, 2003.

19. Tang Z, Li C, Kang B, Gao G, Li C and Zhang Z: GEPIA: A web server for cancer and normal gene expression profiling and interactive analyses. Nucleic Acids Res 45 (W1): W98-W102, 2017

20. Uhlén M, Fagerberg L, Hallström BM, Lindskog C, Oksvold P, Mardinoglu A, Sivertsson Å, Kampf C, Sjöstedt E, Asplund A, et al: Proteomics. Tissue-based map of the human proteome. Science 347: 1260419, 2015.

21. Gao J, Aksoy BA, Dogrusoz U, Dresdner G, Gross B, Sumer SO, Sun Y, Jacobsen A, Sinha R, Larsson E, et al: Integrative analysis of complex cancer genomics and clinical profiles using the cBioPortal. Sci Signal 6: pl1, 2013.

22. Cerami E, Gao J, Dogrusoz U, Gross BE, Sumer SO, Aksoy BA, Jacobsen A, Byrne CJ, Heuer ML, Larsson E, et al: The cBio cancer genomics portal: An open platform for exploring multidimensional cancer genomics data. Cancer Discov 2: 401-404, 2012.

23. Huang da W, Sherman BT and Lempicki RA: Systematic and integrative analysis of large gene lists using DAVID bioinformatics resources. Nat Protoc 4: 44-, 572009.

24. Maere S, Heymans K and Kuiper M: BiNGO: A Cytoscape plugin to assess overrepresentation of gene ontology categories in biological networks. Bioinformatics 21: 3448-3449, 2005.

25. Montojo J,ZuberiK, Rodriguez H,KaziF, Wright G, Donaldson SL Morris Q and Bader GD: GeneMANIA Cytoscape plugin: Fast gene function predictions on the desktop. Bioinformatics 26: 2927-2928, 2010
26. Szklarczyk D, Morris JH, Cook H, Kuhn M, Wyder S, Simonovic M, Santos A, Doncheva NT, Roth A, Bork P, et al: The STRING database in 2017: Quality-controlled protein-protein association networks, made broadly accessible. Nucleic Acids Res 45: D362-D368, 2017.

27. Lu X, Sun W, Tang Y, Zhu L, Li Y, Ou C, Yang C, Su J, Luo C, $\mathrm{Hu} \mathrm{Y}$ and Cao J: Identification of key genes in hepatocellular carcinoma and validation of the candidate gene, cdc25a, using gene set enrichment analysis, meta-analysis and cross-species comparison. Mol Med Rep 13: 1172-1178, 2016.

28. MacDonald JW and Ghosh D: COPA-cancer outlier profile analysis. Bioinformatics 22: 2950-2951, 2006

29. Luo X, Zuo L, Kranzler HR, Wang S, Anton RF and Gelernter J: Recessive genetic mode of an $\mathrm{ADH} 4$ variant in substance dependence in African-Americans: A model of utility of the HWD test. Behav Brain Funct 4: 42, 2008

30. Edenberg HJ, Xuei X, Chen HJ, Tian H, Wetherill LF, Dick DM, Almasy L, Bierut L, Bucholz KK, Goate A, et al: Association of alcohol dehydrogenase genes with alcohol dependence: a comprehensive analysis. Hum Mol Genet 15: 1539-1549, 2006.

31. Edenberg HJ, Jerome RE and Li M: Polymorphism of the human alcohol dehydrogenase $4(\mathrm{ADH} 4)$ promoter affects gene expression. Pharmacogenetics 9: 25-30, 1999.

32. Guindalini C, Scivoletto S, Ferreira RGM, Breen G,Zilberman M, Peluso MA and Zatz M: Association of genetic variants in alcohol dehydrogenase 4 with alcohol dependence in Brazilian patients. Am J Psychiatry 162: 1005-1007, 2005.

33. Luo X, Kranzler HR, Zuo L, Wang S and Gelernter J: Personality traits of agreeableness and extraversion are associated with ADH4 variation. Biol Psychiatry 61: 599-608, 2007.

34. Goode EL, White KL, Vierkant RA, Phelan CM,Cunningham JM, Schildkraut JM, Berchuck A, Larson MC, Fridley BL, Olson JE, et al: Xenobiotic-metabolizing gene polymorphisms and ovarian cancer risk. Mol Carcinog 50: 397-402, 2011.

35. Oze I, Matsuo K, Suzuki T, Kawase T, Watanabe M, Hiraki A, Ito $\mathrm{H}$, Hosono S, Ozawa T, Hatooka S, et al: Impact of multiple alcohol dehydrogenase gene polymorphisms on risk of upper aerodigestive tract cancers in a Japanese population. Cancer Epidemiol Biomarkers Prev 18: 3097-3102, 2009.

36. Wei RR, Zhang MY, Rao HL, Pu HY, Zhang HZ and Wang HY: Identification of ADH4 as a novel and potential prognostic marker in hepatocellular carcinoma. Med Oncol 29: 2737-2743, 2012.

37. Wang X, Yu T, Liao X, Yang C, Han C, Zhu G, Huang K, Yu L, Qin W, Su H, et al: The prognostic value of CYP2C subfamily genes in hepatocellular carcinoma. Cancer Med 7: 966-980, 2018.

38. Gelboin HV and Krausz K: Monoclonal antibodies and multifunctional cytochrome P450: Drug metabolism as paradigm. J Clin Pharmacol 46: 353-372, 2006.

39. Goldstein JA and de Morais SM: Biochemistry and molecular biology of the human CYP2C subfamily. Pharmacogenetics 4: 285-299, 1994

40. Hamman MA, Thompson GA and Hall SD: Regioselective and stereoselective metabolism of ibuprofen by human cytochrome P450 2C. Biochem Pharmacol 54: 33-41, 1997.

41. Jaakkola T, Laitila J, Neuvonen PJ and Backman JT: Pioglitazone is metabolised by CYP2C8 and CYP3A4 in vitro: Potential for interactions with CYP2C8 inhibitors. Basic Clin Pharmacol Toxicol 99: 44-51, 2006

42. Unger T: Inhibiting angiotensin receptors in the brain: Possible therapeutic implications. Curr Med Res Opin 19: 449-451, 2003.

43. Kiang TK, Ping CH, Anari MR, Tong V, Abbott FS and Chang TK: Contribution of CYP2C9, CYP2A6, and CYP2B6 to valproic acid metabolism in hepatic microsomes from individuals with the CYP2C9*1/*1 genotype. Toxicol Sci 94: 261-271, 2006.

44. Tzveova R, Naydenova G, Yaneva T, Dimitrov G, Vandeva S, Matrozova Y, Pendicheva-Duhlenska D, Popov I, Beltheva O, Naydenov C, et al: Gender-specific effect of CYP2C $8 * 3$ on the risk of essential hypertension in bulgarian patients. Biochem Genet 53: 319-333, 2005.

45. Bosó V, Herrero MJ, Santaballa A, Palomar L, Megias JE, de la Cueva H, Rojas L, Marqués MR, Poveda JL, Montalar J and Aliño SF: SNPs and taxane toxicity in breast cancer patients. Pharmacogenomics 15: 1845-1858, 2014.

46. Liu W, Wang B, Ding HU, Wang DW and Zeng H: A potential therapeutic effect of CYP2C8 overexpression on anti-TNF- $\alpha$ activity. Int J Mol Med 34: 725-732, 2014

47. Wei X, Zhang D, Dou X, Niu N, Huang W, Bai J and Zhang G: Elevated 14,15-epoxyeicosatrienoic acid by increasing of cytochrome $\mathrm{P} 4502 \mathrm{C} 8,2 \mathrm{C} 9$ and $2 \mathrm{~J} 2$ and decreasing of soluble epoxide hydrolase associated with aggressiveness of human breast cancer. BMC Cancer 14: 841, 2014. 
48. Yu D, Green B, Marrone A, Guo Y, Kadlubar S, Lin D, Fuscoe J, Pogribny I and Ning B: Suppression of CYP2C9 by microRNA hsa-miR-128-3p in human liver cells and association with hepatocellular carcinoma. Sci Rep 5: 8534, 2015.

49. Wang J, Greene S, Eriksson LC, Reihnér E, Reihner E, Einarsson C, Eggertsen G and Gåfvels M: Human sterol 12a-hydroxylase (CYP8B1) is mainly expressed in hepatocytes in a homogenous pattern. Histochem Cell Biol 123: 441-446, 2005.

50. Björkhem I and Eggertsen G: Genes involved in initial steps of bile acid synthesis. Curr Opin Lipidol 12: 97-103, 2001

51. Xu Y, Li F, Zalzala M, Xu J, Gonzalez FJ, Adorini L, Lee YK, Yin $L$ and Zhang Y: Farnesoid X receptor activation increases reverse cholesterol transport by modulating bile acid composition and cholesterol absorption in mice. Hepatology 64: 1072-1085, 2016.

52. Qin J, Han TQ, Yuan WT, Zhang J, Fei J, Jiang ZY, Niu ZM, Zhang KY, Hua Q, Cai XX, et al: Single nucleotide polymorphism rs 3732860 in the 3'-untranslated region of CYP8B1 gene is associated with gallstone disease in Han Chinese. J Gastroenterol Hepatol 28: 717-722, 2013.

53. Qin J, Jiang ZY, Niu ZM, Zhang KY, Hua Q, Jiang ZH, Wang Y, Huang W, Han TQ and Zhang SD: Association of single nucleotide polymorphism in human CYP8B1 gene with gallstone disease. Zhonghua Yi Xue Za Zhi 91: 2092-2095, 2011 (In Chinese).

54. White DL, Saunders VA, Dang P, Engler J, Venables A, Zrim S, Zannettino A, Lynch K, Manley PW and Hughes T: Most CML patients who have a suboptimal response to imatinib have low OCT-1 activity: Higher doses of imatinib may overcome the negative impact of low OCT-1 activity. Blood 110: 4064-4072, 2007.

55. de Lima LT, Vivona D, Bueno CT, Hirata RD, Hirata MH, Luchessi AD, de Castro FA, de Lourdes F, Chauffaille M, Zanichelli MA, et al: Reduced ABCG2 and increased SLC22A1 mRNA expression are associated with imatinib response in chronic myeloid leukemia. Med Oncol 31: 851, 2014.

56. Singh O, Chan JY, Lin K, Heng CC and Chowbay B: SLC22A1ABCB1 haplotype profiles predict imatinib pharmacokinetics in Asian patients with chronic myeloid leukemia. PLoS One 7: e51771, 2012

57. Rulcova A, Krausova L, Smutny T, Vrzal R, Dvorak Z, Jover R and Pavek P: Glucocorticoid receptor regulates organic cation transporter 1 (OCT1, SLC22A1) expression via HNF4 $\alpha$ upregulation in primary human hepatocytes. Pharmacol Rep 65: 1322-1335, 2013.

58. Herraez E, Lozano E, Macias RI, Vaquero J, Bujanda L, Banales JM, Marin JJ and Briz O: Expression of SLC22A1 variants may affect the response of hepatocellular carcinoma and cholangiocarcinoma to sorafenib. Hepatology 58: 1065-1073, 2013.
59. Lautem A, Heise M, Gräsel A, Hoppe-Lotichius M, Weiler N, Foltys D, Knapstein J, Schattenberg JM, Schad A, Zimmermann A, et al: Downregulation of organic cation transporter 1 (SLC22A1) is associated with tumor progression and reduced patient survival in human cholangiocellular carcinoma. Int J Oncol 42: 1297-1304, 2013.

60. Mehere P, Han Q, Lemkul JA, Vavricka CJ, Robinson H, Bevan DR and Li J: Tyrosine aminotransferase: Biochemical and structural properties and molecular dynamics simulations. Protein Cell 1: 1023-1032, 2010.

61. Maydan G, Andresen BS, Madsen PP, Zeigler M, RaasRothschild A, Zlotogorski A, Gutman A and Korman SH: TAT gene mutation analysis in three Palestinian kindreds with oculocutaneous tyrosinaemia type II; characterization of a silent exonic transversion that causes complete missplicing by exon 11 skipping. J Inherit Metab Dis 29: 620-626, 2006.

62. Bouyacoub Y, Zribi H, Azzouz H, Nasrallah F, Abdelaziz RB, Kacem M, Rekaya B, Messaoud O, Romdhane L, Charfeddine C, et al: Novel and recurrent mutations in the TAT gene in Tunisian families affected with Richner-Hanhart syndrome. Gene 529: 45-49, 2003.

63. Fu L, Dong SS, Xie YW, Tai LS, Chen L, Kong KL, Man K, Xie D, Li Y, Cheng Y, et al: Down-regulation of tyrosine aminotransferase at a frequently deleted region $16 \mathrm{q} 22$ contributes to the pathogenesis of hepatocellular carcinoma. Hepatology 51: 1624-1634, 2010.

64. Su W, Wang Y, Jia X, Wu W, Li L, Tian X, Li S, Wang C, Xu H, Cao J, et al: Comparative proteomic study reveals $17 \beta-\mathrm{HSD} 13$ as a pathogenic protein in nonalcoholic fatty liver disease. Proc Natl Acad Sci USA 111: 11437-11442, 2014.

65. Fujimoto Y, Itabe H, Sakai J, Makita M, Noda J, Mori M, Higashi Y, Kojima $S$ and Takano T: Identification of major proteins in the lipid droplet-enriched fraction isolated from the human hepatocyte cell line HuH7. Biochim Biophys Acta 1644: 47-59, 2004.

66. Chen J, Zhuo JY, Yang F, Liu ZK, Zhou L, Xie HY, Xu X and Zheng SS: 17-beta-hydroxysteroid dehydrogenase 13 inhibits the progression and recurrence of hepatocellular carcinoma. Hepatobiliary Pancreat Dis Int 17: 220-226, 2018.

(i) $\Theta$ This work is licensed under a Creative Commons Attribution-NonCommercial-NoDerivatives 4.0 International (CC BY-NC-ND 4.0) License. 